\title{
Elliptical FRP-Concrete-Steel Double-Skin Tubular Columns under Monotonic Axial Compression
}

\author{
Bing Zhang $\mathbb{D}^{1},{ }^{1}$ Gui-Sen Feng, ${ }^{1,2}$ Yan-Lei Wang, ${ }^{3}$ Cong-Cong Lai, ${ }^{1}$ Chen-Chen Wang, \\ and Xia-Min Hu ${ }^{1}$ \\ ${ }^{1}$ College of Civil Engineering, Nanjing Tech University, Nanjing, China \\ ${ }^{2}$ Shandong Tong Yuan Design Group, Jinan, China \\ ${ }^{3}$ School of Civil Engineering, Dalian University of Technology, Dalian, China
}

Correspondence should be addressed to Bing Zhang; zhangb@njtech.edu.cn

Received 14 September 2019; Accepted 15 October 2019; Published 24 January 2020

Guest Editor: Tianyu Xie

Copyright (c) 2020 Bing Zhang et al. This is an open access article distributed under the Creative Commons Attribution License, which permits unrestricted use, distribution, and reproduction in any medium, provided the original work is properly cited.

Hybrid FRP-concrete-steel double-skin tubular columns (hybrid DSTCs) are a novel form of hollow columns consisting of an outer FRP tube, an inner steel tube, and an annular layer of concrete between the two tubes. Due to the effective confinement of the two tubes, the concrete in hybrid DSTCs is well confined, leading to excellent ductility and strength enhancement. Hybrid DSTCs also have excellent corrosion resistence due to the effective protection of the outer FRP tube. However, existing studies mainly focused on hybrid DSTCs with a circular cross-section. When subjecting to different loads in the two horizontal directions, elliptical columns are preferred as they can provide different bending stiffness and moment capacity around two axes of symmetry without significantly reducing the confining effect of the FRP tube. This paper extends the existing work on circular DSTCs to elliptical DSTCs with a particular focus on four issues: the effect of elliptical aspect ratio (i.e., the ratio of the major axis to the minor axis of the outer elliptical cross-section), the effect of the FRP tube thickness, the effect of void area ratio (i.e., the ratio of the area of concrete void to the area of the outer elliptical section), and the effect of the cross-section of the inner steel tube (i.e., both rectangular and elliptical steel tubes were used). Experimental results show that, the averaged peak stress of the confined concrete in elliptical DSTCs increases with the increase in the elliptical aspect ratio, whereas the elliptical aspect ratio has no obvious effect on the ultimate axial strain; the cross-section shape of the inner steel tube has significant effect on the axial stress-strain behavior of the confined concrete in elliptical DSTCs; elliptical DSTCs with an elliptical steel tube exhibit much better ductility and strength enhancement than those specimens with a rectangular steel tube. A simple stress-strain model of confined concrete was proposed for elliptical DSTCs to account for the effects of the elliptical aspect ratio, the inner void, and the shape of the inner steel tube, which can provide reasonably accurate but conservative predictions.

\section{Introduction}

Fiber-reinforced polymer (FRP) composites have many advantages compared with traditional building materials (i.e., concrete and steel), such as high strength-weight ratio and excellent corrosion resistance. FRP composites have found increasing applications in civil engineering, both in the retrofitting of existing reinforced concrete structures (e.g., bonding FRP composites to concrete beams to enhance their bending strength or shear strength; wrapping FRP composites on concrete columns to improve their ductility under seismic loading) and in the construction of new structures incorporating with FRP (e.g., FRP decks for footbridges; FRP domes for radar equipment; concrete-filled FRP tubes as bridge piles) [1-3]. Extensive studies have been conducted to explore the possibilities of constructing new structures using FRP composites [4-7], in which traditional materials (e.g., concrete and steel) are combined with FRP composites to create novel hybrid structures. The word hybrid rather than composite is used here to indicate the combined use of traditional materials and FRP composites to prevent any confusion or misunderstanding as FRP itself is a composite material consisting of both fibers and resin matrix.

Hybrid FRP-concrete-steel double-skin tubular columns (hybrid DSTCs), which combine concrete, steel, and FRP composites in an optimal manner, were invented at the Hong Kong 


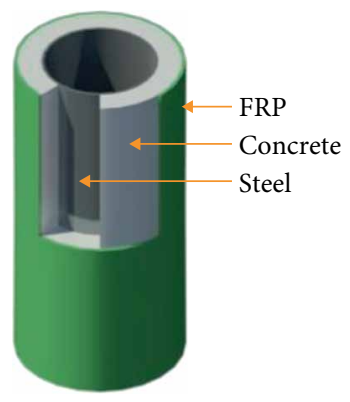

(a)

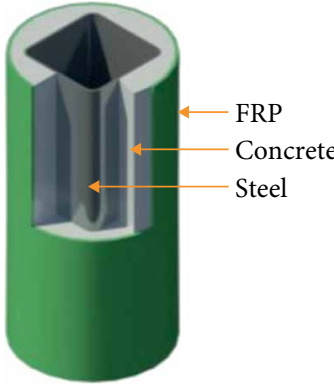

(b)

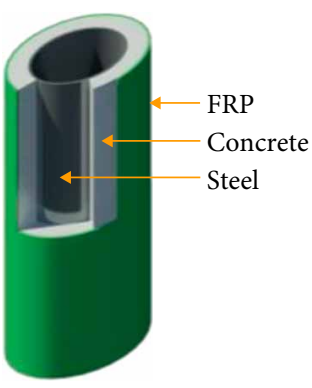

(c)

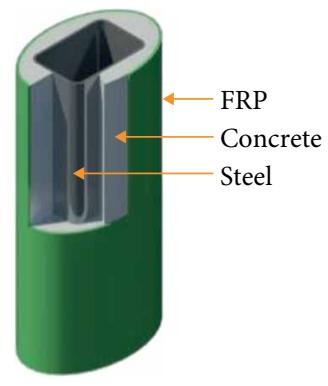

(d)

FIGURE 1: Hybrid DSTCs. (a) Circular DSTCs with a circular steel tube. (b) Circular DSTCs with a square steel tube. (c) Elliptical DSTCs with an elliptical steel tube. (d) Elliptical DSTCs with a rectangular steel tube.

Polytechnic University in 2004 [8, 9]. Hybrid DSTCs consist of an inner steel tube, an annular layer of concrete, and an outer FRP tube (Figure 1(a)). The inner steel tube provides the main longitudinal reinforcement for hybrid DSTCs and also prevents the concrete from inward spalling during the earthquake. The outer FRP tube usually consists of fibers oriented in the hoop direction or close to the hoop direction to confine the concrete and to enhance the seismic performance of the member. To reduce the construction cost, the outer FRP tube and the inner steel tube could also be used as the in-situ mold for the concrete casting. Hybrid DSTCs are quite suitable for structural members in harsh environments due to their excellent corrosion resistance, which is enabled by the use of the outer FRP tube. Hybrid DSTCs are also particularly attractive for use in seismic regions due to their excellent energy dissipation ability under earthquake loading.

Teng et al. [8,9] presented the first-ever experimental study on hybrid DSTCs under axial compression and explained the rationale and advantages of hybrid DSTCs in detail. Since then, hybrid DSTCs have received extensive research attention from researchers. Existing research on hybrid DSTCs mainly covers the following aspects: (1) hybrid DSTCs under monotonic axial compression [8-16]; (2) hybrid DSTCs under cyclic axial compression [17-19]; (3) hybrid DSTCs under eccentric compression [20, 21]; (4) hybrid DSTCs subjected to combined axial compression and cyclic lateral loading [22-25]; (5) hybrid DSTCs under lateral impact loading [26, 27]. Yu [10] presented the first systematic study of hybrid DSTCs under axial compression, in which small-scale specimens with normal strength concrete (NSC) were tested. Yu's [10] work confirmed the concrete in hybrid DSTCs is very effectively confined by the two tubes, and the local buckling of the inner steel tube is either delayed or suppressed by the surrounding concrete, leading to a very ductile response. Hybrid DSTCs constructed with high strength concrete (HSC) was first reported in Zhang et al. [12], which confirmed that hybrid DSTCs still possess excellent ductility if the FRP tube has sufficient confinement stiffness and sufficient rupture strain capacity. Zhang et al. [16] conducted a study on large-scale hybrid DSTCs subjected to combined axial compression and cyclic lateral loading, which indicates that hybrid DSTCs possess excellent ductility and seismic resistance even when high strength concrete with a cylinder compressive strength of around $120 \mathrm{MPa}$ is used. Wang et al. [26] tested hybrid DSTCs under lateral impact loading using a drop hammer testing facility and confirmed the excellent energy dissipation ability of hybrid DSTCs. Some variations of hybrid DSTCs were also investigated experimentally, including (1) use of light-weight concrete [28]; (2) use of recycled aggregate concrete [29]; (3) use of ribbed steel tubes [30]; (4) use of high-strength steel tubes [31]; (5) use of large-rupture-strain FRP tubes [32].

Existing studies, however, are mostly focused on hybrid DSTCs with a circular cross-section (i.e., the cross-section of the outer FRP tube is circular) (Figures 1(a) and 1(b)). Although circular DSTCs are attractive as bridge piers, elliptical DSTCs are preferred when the column is subjected to different loads in the two horizontal directions. Elliptical DSTCs can provide different bending stiffness and moment capacity around two axes of symmetry without significantly reducing the confining effect of the FRP tube [33]. To extend the existing study on hybrid DSTCs, the present study presents an experimental study of elliptical DSTCs under monotonic axial compression with a particular focus on four issues: the effect of elliptical aspect ratio $\rho_{A}$ (i.e., the ratio of the major axis to the minor axis of the outer elliptical cross-section), the effect of the FRP tube thickness $t_{\text {frp }}$, the effect of the void area ratio $\varphi_{A}$ (i.e., the ratio of the area of the concrete void to the area of the outer elliptical section), and the effect of the cross-section of the inner steel tube (i.e., both rectangular and elliptical steel tubes were used, Figures 1(c) and 1(d)).

\section{Experimental Program}

2.1. Specimen Details. In the present study, elliptical DSTCs with a height of $600 \mathrm{~mm}$ were fabricated and tested. These specimens could be divided into two groups based on the cross-section of steel tubes: (1) elliptical DSTCs with an elliptical inner steel tube (referred to as EE-DSTCs) (Figure 2); (2) elliptical DSTCs with a rectangular inner steel tube (referred to as ER-DSTCs) (Figure 3). Specimen details are summarized in Table 1 and cross-sectional configurations are shown in Figures 2 and 3. For all specimens, the major axis $2 \mathrm{a}$ of the outer elliptical cross-section was $300 \mathrm{~mm}$, while the minor axis $2 b$ was 300,250 , or $200 \mathrm{~mm}$, leading to three different elliptical aspect ratios $\rho_{A}=2 a / 2 b$ (i.e., 1.0, 1.2, or 1.5). Specimens which have an elliptical aspect ratio $\rho_{A}$ of 1.0 are circular DSTCs (i.e., EC1-ec1-F6 and EC1-rc1-F6 as 


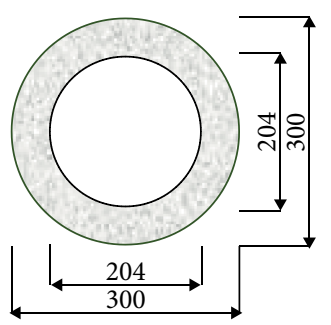

(a)

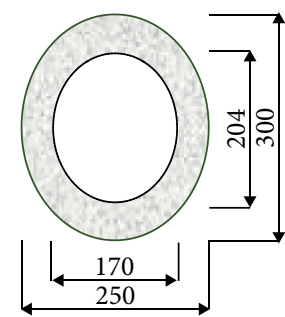

(b)

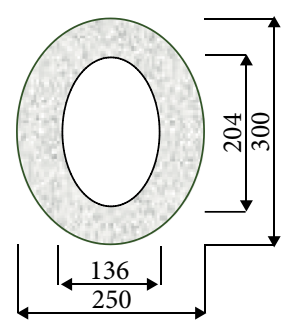

(c)

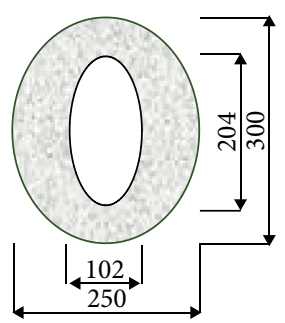

(d)

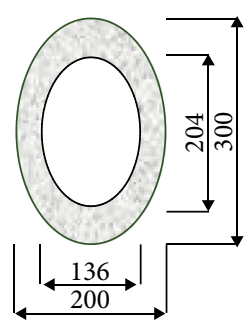

(e)

FIGURE 2: Elliptical DSTCs with an elliptical steel tube. (a) EC1-ec1-F6. (b) EC2-ec2-F3 and EC2-ec2-F6. (c) EC2-ec3-F6. (d) EC2-ec4-F6. (e) EC3-ec3-F3 and EC3-ec3-F6.

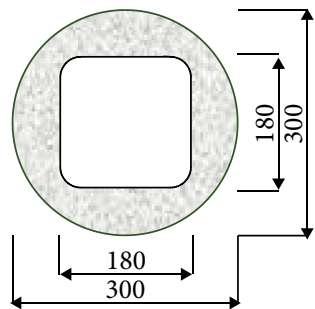

(a)

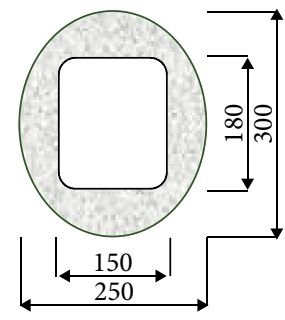

(b)

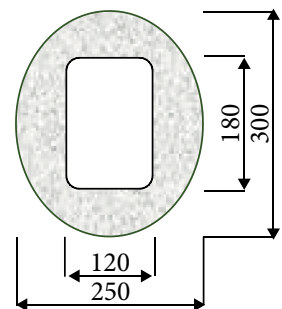

(c)

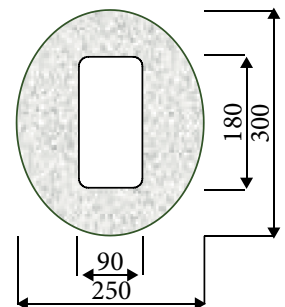

(d)

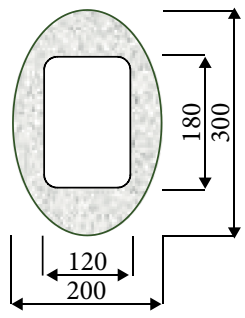

(e)

FIGURE 3: Elliptical DSTCs with a rectangular steel tube. (a) EC1-rc1-F6. (b) EC2-rc2-F3 and EC2-rc2-F6. (c) EC2-rc3-F6. (d) EC2-rc4-F6. (e) EC3-rc3-F3 and EC3-rc3-F6.

TABLE 1: Specimen details.

\begin{tabular}{|c|c|c|c|c|c|c|}
\hline \multirow{2}{*}{ Specimen } & \multicolumn{3}{|c|}{ Outer elliptical dimensions } & \multirow{2}{*}{ Type of inner steel tube } & \multirow{2}{*}{ FRP thickness $t_{\text {frp }}(\mathrm{mm})$} & \multirow{2}{*}{ Void area ratio $\varphi_{A}$} \\
\hline & $2 \mathrm{a}(\mathrm{mm})$ & $2 \mathrm{~b}(\mathrm{~mm})$ & $\rho_{A}=2 \mathrm{a} / 2 \mathrm{~b}$ & & & \\
\hline EC1-ec1-F6 & 300 & 300 & 1.0 & ec1 & 2.10 & 0.46 \\
\hline EC2-ec2-F3 & 300 & 250 & 1.2 & ec2 & 1.05 & 0.46 \\
\hline EC2-ec2-F6 & 300 & 250 & 1.2 & ec2 & 2.10 & 0.46 \\
\hline EC2-ec3-F6 & 300 & 250 & 1.2 & ec3 & 2.10 & 0.37 \\
\hline EC2-ec4-F6 & 300 & 250 & 1.2 & ec4 & 2.10 & 0.28 \\
\hline EC3-ec3-F3 & 300 & 200 & 1.5 & ec3 & 1.05 & 0.46 \\
\hline EC3-ec3-F6 & 300 & 200 & 1.5 & ec3 & 2.10 & 0.46 \\
\hline $\mathrm{EC} 1-\mathrm{rc} 1-\mathrm{F} 6$ & 300 & 300 & 1.0 & $\mathrm{rcl}$ & 2.10 & 0.46 \\
\hline $\mathrm{EC} 2-\mathrm{rc} 2-\mathrm{F} 3$ & 300 & 250 & 1.2 & rc2 & 1.05 & 0.46 \\
\hline EC2-rc2-F6 & 300 & 250 & 1.2 & rc2 & 2.10 & 0.46 \\
\hline EC2-rc3-F6 & 300 & 250 & 1.2 & rc3 & 2.10 & 0.37 \\
\hline EC2-rc4-F6 & 300 & 250 & 1.2 & $\mathrm{rc} 4$ & 2.10 & 0.28 \\
\hline EC3-rc3-F3 & 300 & 200 & 1.5 & $\mathrm{rc} 3$ & 1.05 & 0.46 \\
\hline EC3-rc3-F6 & 300 & 200 & 1.5 & $\mathrm{rc3}$ & 2.10 & 0.46 \\
\hline
\end{tabular}

shown in Figure 2(a) and 3(a), respectively). For EE-DSTCs, four types of elliptical steel tubes were used, which had the same length of major axis $2 a_{s}$ (i.e., $204 \mathrm{~mm}$ ), but four different minor axes $2 b_{s}$ (i.e., 204, 170, 136 and $102 \mathrm{~mm}$ ) (Figure 2, Table 2). For RE-DSTCs, four types of rectangular steel tubes were used, which had the same corner radius of $20 \mathrm{~mm}$, the same breadth $l_{s}$ of the steel rectangular cross-section (i.e., $180 \mathrm{~mm}$ ), but four different widths $w_{s}$ (i.e., 180, 150, 120 and $90 \mathrm{~mm}$ ) (Figure 3, Table 3).

For ease of reference, each specimen is given a name (Table 1), which consists of three parts: (1) the first part "EC1" "EC2" and "EC3" indicate the elliptical aspect ratio $\rho_{A}$ to be "1.0" "1.2" and "1.5", respectively; (2) the second part
TABLE 2: Details of elliptical steel tubes.

\begin{tabular}{lcccccc}
\hline Type & $\begin{array}{c}2 a_{s} \\
(\mathrm{~mm})\end{array}$ & $\begin{array}{c}2 b_{s} \\
(\mathrm{~mm})\end{array}$ & $a_{s} / b_{s}$ & $\begin{array}{c}f_{y} \\
(\mathrm{MPa})\end{array}$ & $\begin{array}{c}E_{s} \\
(\mathrm{GPa})\end{array}$ & $\begin{array}{c}f_{u} \\
(\mathrm{MPa})\end{array}$ \\
\hline $\mathrm{ec} 1$ & 204 & 204 & 1.0 & & & \\
$\mathrm{ec} 2$ & 204 & 170 & 1.2 & & & \\
$\mathrm{ec} 3$ & 204 & 136 & 1.5 & 302.6 & 201.0 & 441 \\
$\mathrm{ec} 4$ & 204 & 102 & 2.0 & & & \\
\hline
\end{tabular}

starts with "ec" or "rc" to indicate the cross-sectional shape of the steel tube to be elliptical or rectangular, followed by a digit to indicate the steel tube type as described in Tables 2 
TABLE 3: Details of rectangular steel tubes.

\begin{tabular}{lcccccc}
\hline Type & $l_{s}(\mathrm{~mm})$ & $\begin{array}{c}w_{s} \\
(\mathrm{~mm})\end{array}$ & $l_{s} / w_{s}$ & $\begin{array}{c}f_{y} \\
(\mathrm{MPa})\end{array}$ & $\begin{array}{c}E_{s} \\
(\mathrm{GPa})\end{array}$ & $\begin{array}{c}f_{u} \\
(\mathrm{MPa})\end{array}$ \\
\hline $\mathrm{rc} 1$ & 180 & 180 & 1.0 & & & \\
$\mathrm{rc} 2$ & 180 & 150 & 1.2 & 308.0 & 200.3 & 459 \\
$\mathrm{rc} 3$ & 180 & 120 & 1.5 & & & \\
$\mathrm{rc} 4$ & 180 & 90 & 2.0 & & & \\
\hline
\end{tabular}

and 3 ; (3) the third part has a letter "F" and one digit to indicate the fiber sheet layers of the FRP tube. The nominal thickness of each layer fiber sheet was $0.35 \mathrm{~mm}$, leading to two FRP tube thicknesses for these specimens (i.e., $1.05 \mathrm{~mm}$ and $2.10 \mathrm{~mm}$ ).

All elliptical and rectangular steel tubes in the present study had the same thickness (i.e., $4.5 \mathrm{~mm}$ ). The FRP tube of all specimens was formed by wrapping continuous unidirectional glass/epoxy laminates on the hardened concrete surface with the fibers oriented in the hoop direction. For each FRP tube, there was an overlapping zone spanning a circumferential distance of $150 \mathrm{~mm}$ (Figure 4). Additional FRP strips with a width of $40 \mathrm{~mm}$ were provided near the two ends of the specimens to prevent premature failure there. Compared with FRP-confined solid columns, hybrid DSTCs can save concrete significantly due to the inner void, which could be indicated by the void area ratio $\varphi_{A}$ (i.e., the ratio of the area of the concrete void to the area of the outer elliptical section). Two groups of elliptical DSTCs were prepared to investigate the effect of the void area ratio $\varphi_{A}$ (i.e., EC2-rc2-F6, EC2-rc3-F6, and EC2-rc4-F6; EC2-ec2-F6, EC2-ec3-F6, and EC2-ec4-F6). To investigate the effect of the cross-section shape of the inner steel tube, for each elliptical DSTC with an elliptical inner steel tube, there was a companion elliptical DSTC with a rectangular inner steel tube, which had the same aspect ratio, the same FRP tube thickness, and the same void area ratio (e.g., EC2-rc2-F6 and EC2-ec2-F6 are a pair of elliptical DSTCs for comparison).

\subsection{Material Properties}

2.2.1. Concrete. Self-compacting concrete (SCC) was adopted to ensure the quality of the concrete casting. Three plain concrete cylinders $(150 \mathrm{~mm}$ in diameter and $300 \mathrm{~mm}$ in height) were prepared and tested under a displacementcontrolled loading rate of $0.18 \mathrm{~mm} / \mathrm{mm}$ to obtain the compressive properties of unconfined concrete according to ASTM C39/C39M [34]. The elastic modulus $E_{c}$, the peak stress $f_{c o}$, and the axial strain at peak stress $\varepsilon_{c o}$ averaged from these concrete cylinder tests are $33.6 \mathrm{GPa}, 50.4 \mathrm{MPa}$, and $0.26 \%$, respectively.

2.2.2. FRP. To determine the material properties of the FRP tube for these specimens, tensile tests were conducted on six flat coupons according to ASTM D3039/D3039M [35]. The FRP coupon, which contained two layers of fiber sheets, was fabricated using the same wet-layup technique as the FRP tube for elliptical DSTCs. The elastic modulus $E_{f r p}$, the ultimate strength and the ultimate strain averaged from these
FRP flat coupon tests are $80.1 \mathrm{GPa}, 1836.2 \mathrm{MPa}$, and 2.29\%, respectively.

2.2.3. Steel Tube. As mentioned above, there were four types of elliptical steel tubes and four types of rectangular steel tubes for elliptical DSTCs (Tables 2 and 3). All elliptical steel tubes were fabricated using the same batch of raw materials, whereas all rectangular steel tubes were manufactured using another batch of raw materials. All these steel tubes were manufactured following four steps: (1) cutting a flat steel plate to designed dimensions; (2) bending the flat steel plate to form half part of a steel tube; (3) welding two identical half parts together by two longitudinal welds; (4) milling the two ends of each steel tube to achieve flat ends which are perpendicular to its axis. Tensile tests on five steel coupons were conducted following BS 18 [36] for elliptical steel tubes and rectangular steel tubes, respectively. Test results showed the tensile stress-strain curves of these steel coupons had a long yield plateau and then a hardening branch before the final rupture. The average elastic modulus $E_{s}$, the average yield stress $f_{y}$ and the average ultimate tensile strength $f_{u}$ are shown in Tables 2 and 3 .

In addition, for each type of these steel tubes, two hollow steel tubes, which had the same height as those used in elliptical DSTCs (i.e., $600 \mathrm{~mm}$ ), were tested under monotonic axial compression. On the outer surface of each steel tube, four hoop strain gauges and four axial strain gauges with a gauge length of $20 \mathrm{~mm}$ were installed at the midheight uniformly distributed along the circumferential direction. Four LVDTs were installed to measure the overall axial shortening of each steel tube. The failed steel tubes after axial compression tests and the axial stress-axial strain curves are all shown in Figures 5 and 6 , with the axial strain being obtained from LVDTs. As shown in Figure 5, steel tube ec1 showed an elephant foot buckling failure mode which is typical for circular steel tubes, whereas other elliptical steel tubes showed local buckling failures near the midheight of the steel tube. The axial stress-strain curves of elliptical steel tubes exhibited an ascending branch and a slowly descending branch. As shown in Figure 6, all rectangular steel tubes showed local inward/outward buckling failure, and their axial stress-strain curves exhibited a linear ascending branch and then a descending branch after the peak stress point. As shown in Figures 5 and 6 , the peak stresses of these steel tubes were much lower than the ultimate tensile strength $f_{u}$ obtained from the flat steel coupon tests, which was mainly due to the local buckling failure of these steel tubes.

2.3. Experimental Setup and Instrumentation. Figure 4 shows the experimental setup and instrumentation for all specimens. Six LVDTs were installed to measure the axial deformation of each specimen. Of the six LVDTs, four (i.e., LVDT-300) were used to measure the shortening of the 300$\mathrm{mm}$ midheight region, while the other two (i.e., LVDT-600) were used to measure the total shortening of the specimen. For the outer FRP tube, four axial strain gauges were installed at the midheight of the specimen uniformly distributed along the circumference of the elliptical cross-section; in addition, ten hoop strain gauges were also installed at the midheight as shown in Figure 4(a). At the midheight of the inner steel tube 


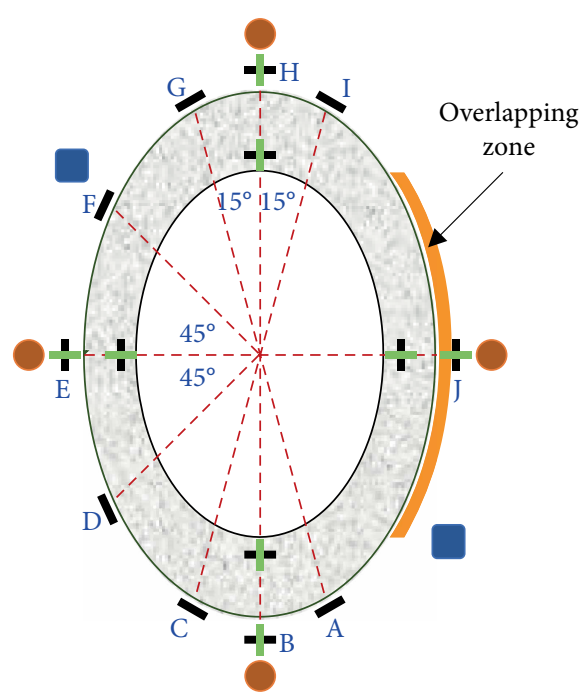

EE-DSTCs

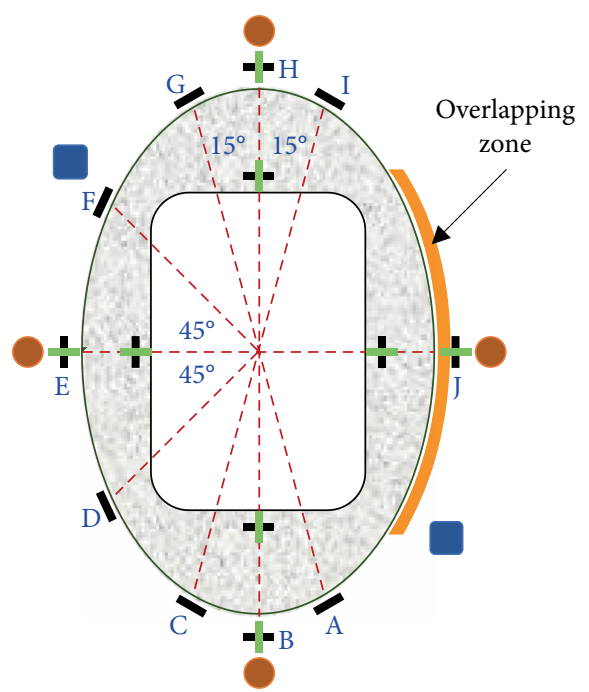

ER-DSTCs
LVDT-600
LVDT-300
- Strain gauge in the hoop direction
- Strain gauge in the longitudinal direction

(a)

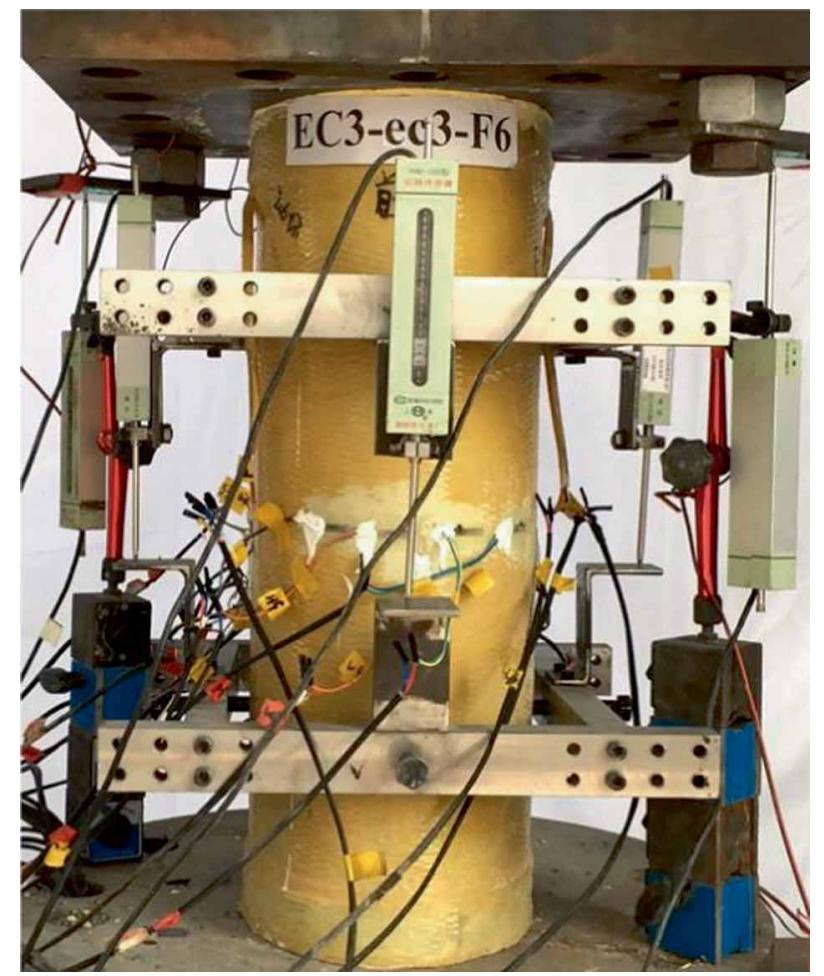

(b)

FIGURE 4: Experimental set-up and instrumentation. (a) Planar view of strain gauges and LVDTs. (b) Experimental set-up.

of elliptical DSTCs, four hoop strain gauges and four axial strain gauges with a gauge length of $20 \mathrm{~mm}$ were installed and distributed evenly over the circumference. A large column testing facility (maximum capacity of $10,000 \mathrm{kN}$ ) was used to conduct axial compression tests with a displacement control rate of $0.36 \mathrm{~mm} / \mathrm{min}$. All the test data, including strains, loads, and displacements, were recorded simultaneously by a data acquiring system.

\section{Test Results and Discussions}

3.1. General. A small preload was applied to each specimen to check the concentric loading condition and then was removed before the axial compression test. At the initial stage of the loading test, readings of the four axial strains on the FRP tube were quite uniform, and there was no obvious phenomenon on the outer FRP tube. When the axial strain readings exceeded 


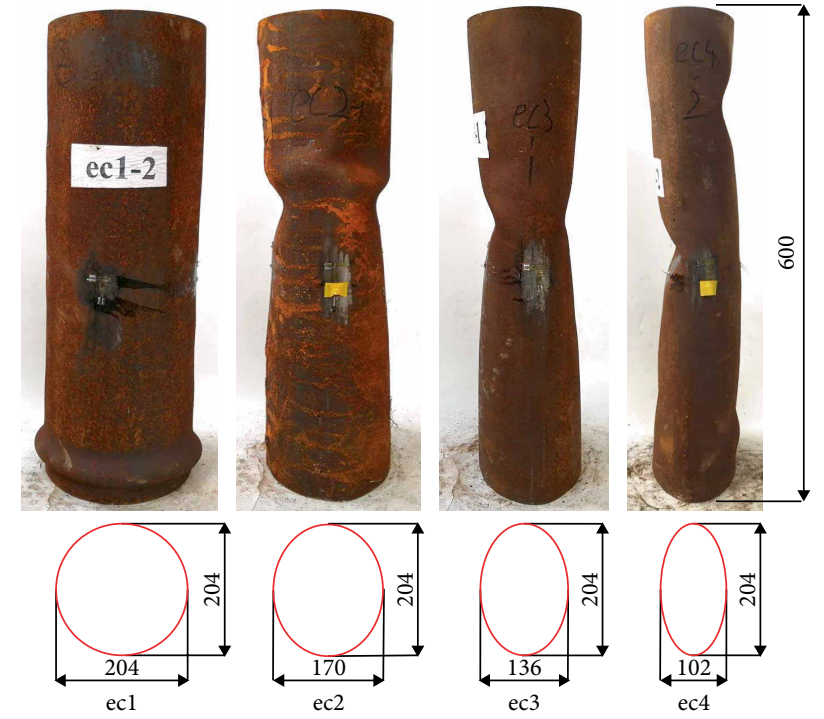

(a)

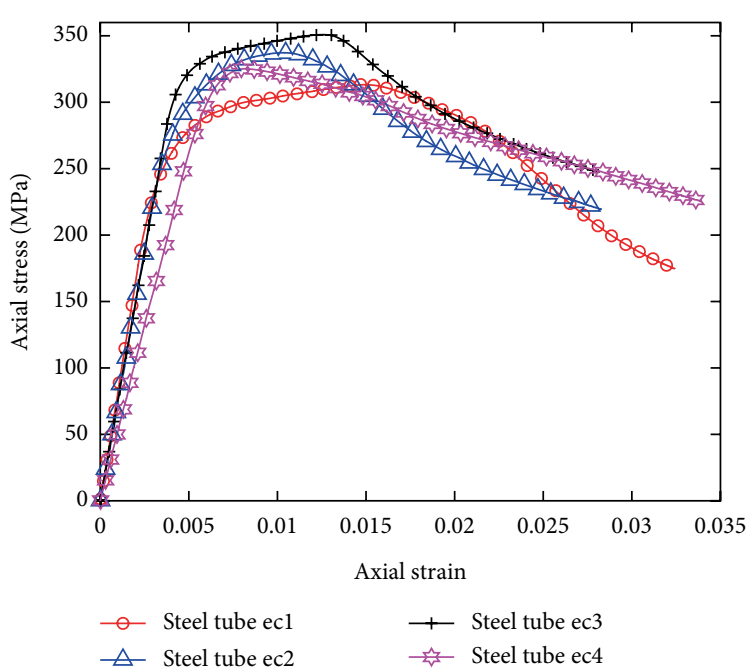

(b)

Figure 5: Axial compression test of elliptical hollow steel tubes. (a) Elliptical hollow steel tubes. (b) Axial stress-strain curves.
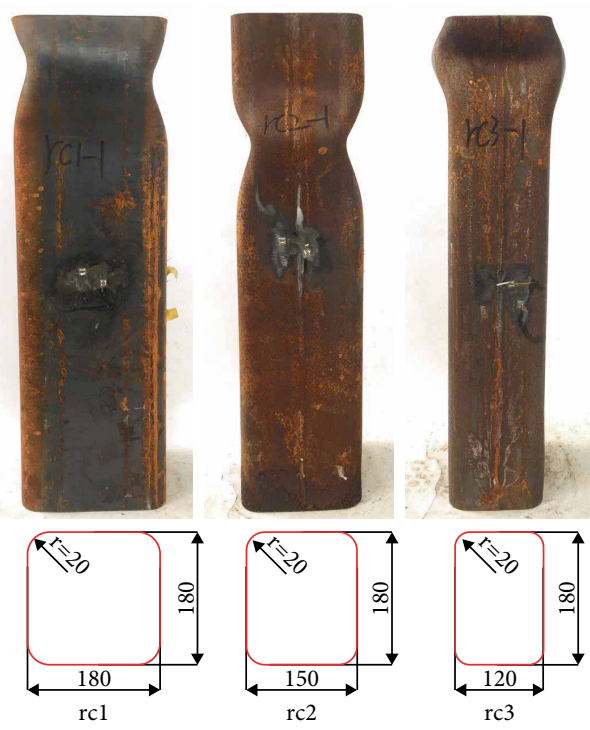

(a)

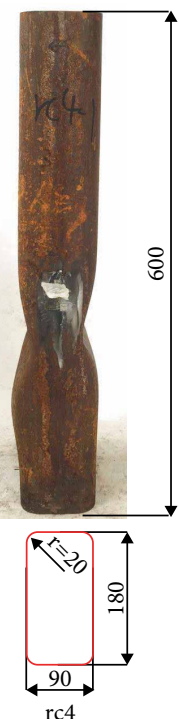

$\mathrm{rc4}$

FIGURE 6: Axial compression test of rectangular hollow steel tubes.

around $0.03 \%$, a loud noise was noticed emitting from the specimens, suggesting that severe damage had occurred in the concrete. As the loading process progressed, the hoop strain readings of these strain gauges near the ends of the major axis of elliptical cross-section (i.e., strain gauges A, B, C, G, H, I in Figure 4(a)) generally increased faster than the rest hoop strain gauges, indicating the FRP tube provided more effective confinement there. Before the rupture of the FRP tube, noticeable damages were observed on the outer surface of the FRP tube, which were generally close to the ends of the major axis of the elliptical cross-section. At the final stage of the loading test, progressive snapping noise of fibers was noticed and finally, the explosive rupture of FRP tube occurred associated with a big noise.

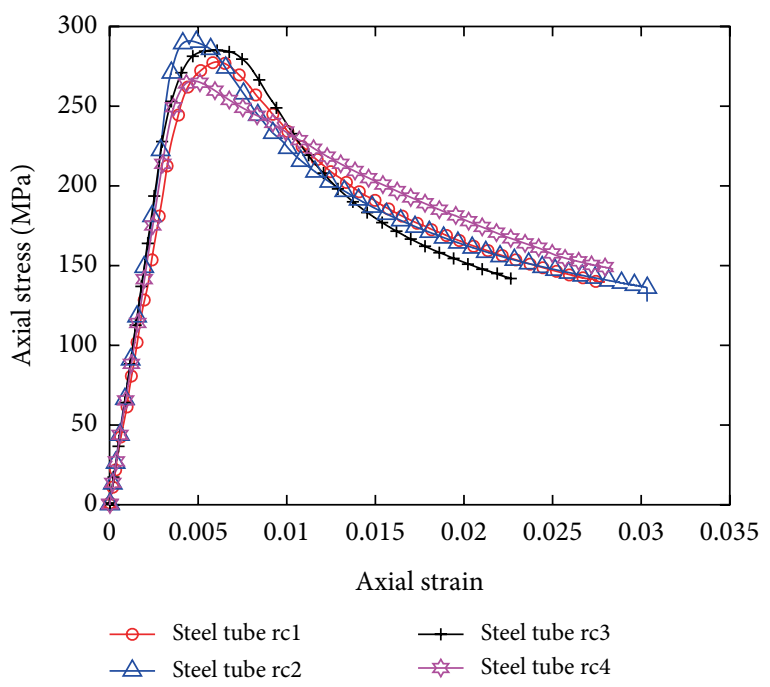

(b)

(a) Rectangular hollow steel tubes. (b) Axial stress-strain curves.

After the test, the damage of the FRP tube and the inner steel tube was carefully examined (Figure 7). The ruptures of the FRP tube, which was mainly due to the hoop tension induced by the dilation of the inner concrete, were generally close to the ends of the major axis of the elliptical cross-section. As expected, the concrete layer also suffered severe crushing at the locations where FRP ruptures occurred. Severe inward deformation and local buckling, which was generally close to the localized damage of the FRP tube, was noticed for the inner steel tubes. It is evident that the inward buckling of rectangular steel tubes was much severe than that of elliptical steel tubes (Figure 7).

3.2. Axial Load-Axial Strain Curves. As the axial strain gauges were on the outer surface of the FRP tube and the 
steel tube, their readings may not closely reflect the strain state of the confined concrete especially after the development of significant localized damage on the FRP tube and the local buckling of the steel tube. The axial strain obtained from the LVDTs cover the total height of the specimen (i.e., LVDT600) may not reflect the strain state of the confined concrete especially at the early stage of the axial compression as there may be initial gaps between the loading plates and the two ends of the specimen. In this paper, the axial strain found from LVDT-300, which reflects the average axial strain of the $300-\mathrm{mm}$ midheight region, is used to represent the axial strain of these specimens. Axial load-axial strain curves of all specimens are shown in Figure 8 in two groups. As shown in Figure 8(a), the axial load-axial strain curves of EE-DSTCs exhibit an ascending linear branch and a smooth curve transition at the axial strain of around $0.3 \%$, then followed by a second ascending branch. In contrast, the second branch of ER-DSTCs is approximately a plateau with a staled load (Figure 8(b)). For some ER-DSTCs (e.g., specimens EC1-rc1-F6 and EC2-rc2-F6), the second branch is a slightly descending curve.

3.3. Key Test Results. As introduced above, the elliptical FRP tubes of these elliptical DSTCs only had fibers oriented in the hoop direction. Therefore, the direct load contribution of the FRP tube is ignored in the present study. For elliptical DSTCs, the direct load contribution of inner steel tubes should be considered when obtaining the axial load resisted by the concrete. The axial load resisted by the concrete in elliptical DSTCs is assumed to be equal to the axial load resisted by the specimen subtracted by the axial load resisted by the inner steel tube at the same axial strain. The axial load carried by the inner steel tube was assumed to be the same as the hollow steel tubes under axial compression (Figures 5 and 6). The axial loads of the specimen, the concrete, and the steel tube are illustrated for two typical elliptical DSTCs in Figure 9. The average axial stress of the confined concrete in elliptical DSTCs is obtained as the load resisted by the concrete divided by the cross-section area of the concrete.

The key test results of all specimens are summarized in Table 4. $P_{\max }$ is the peak axial load of the specimen obtained from the test. $f_{c c}$ is the peak axial stress of the confined concrete. $\varepsilon_{c u}$ is the ultimate axial strain of the specimen when the FRP tube ruptured. $\varepsilon_{\text {hrup }}$ is the rupture strain of the FRP tube averaged from the hoop strain gauges outside of the overlapping zone. Some of the hoop strain gauges, which failed to work before the rupture of the FRP tube, were excluded from the calculation of the average hoop rupture strain $\varepsilon_{\text {hrup }} \cdot \varepsilon_{\text {hrup,max }}$ is the maximum hoop rupture strain found from the ten hoop strain gauges on the midheight of the FRP tube. The planar location of the hoop strain gauge with the maximum hoop rupture strain $\varepsilon_{\text {hrup,max }}$ could be found in Figure 4(a) and Table 4. It is evident that the maximum hoop rupture strain $\varepsilon_{\text {hrup,max }}$ mostly occurred near the ends of the major axis of the elliptical cross-section. $f_{c c} / f_{c o}$ and $\varepsilon_{c u} / \varepsilon_{c o}$ is the strength enhancement ratio and the strain enhancement ratio of the confined concrete, respectively.

3.4. Effect of Elliptical Aspect Ratio. As shown in Figure 10, axial stress-strain curves of the confined concrete of elliptical
DSTCs are examined to evaluate the effect of the elliptical aspect ratio. Elliptical DSTCs in each subfigure had the same FRP tube thickness (i.e., the nominal thickness of FRP tube is $2.10 \mathrm{~mm}$ ) and the same void area ratio (i.e., 0.46 ), but different elliptical aspect ratios. As shown in Figure 10, the averaged stress of the confined concrete increases with the increase in the elliptical aspect ratio, whereas the elliptical aspect ratio has no obvious effect on the ultimate axial strain. For an elliptical DSTC with a larger aspect ratio, the concrete at region A of the elliptical cross-section (i.e., the region of the concrete between the FRP tube and the steel tube along the direction of the major axis of the elliptical section) is under more effective confinement due to the larger local curvature of the FRP tube, leading to higher strength enhancement there (Figure 10).

3.5. Effect of FRP Tube Thickness. As shown in Figure 11, four pairs of elliptical DSTCs, which have the same elliptical aspect ratio, the same void ratio but a different FRP tube thickness, are compared to investigate the effect of FRP tube thickness. It is well known that the response of concrete confined by FRP is significantly affected by the confinement stiffness and the hoop rupture strain of the FRP tube. A thicker FRP tube generally has larger strength enhancement and ductility improvement. As shown in Table 4, the strength enhancement ratio $f_{c c} / f_{c o}$ and the strain enhancement ratio $\varepsilon_{c u} / \varepsilon_{c o}$ of these specimens with a 6-layer FRP tube are much higher than those of companion specimens with a 3-layer FRP tube. It is evident that FRP tube thickness has a significant effect on the axial stress-strain curves of Elliptical DSTCs: a thicker FRP tube leads to higher peak stress and larger ultimate axial strain for the confined concrete in elliptical DSTCs. For EE-DSTCs, it is also evident that a thicker FRP tube leads to a higher stiffness for the second portion of the axial stress-strain curve of the confined concrete (Figures 11(a) and 11(b)).

3.6. Effect of Void Area Ratio. The effect of the void ratio can be examined by comparing the stress-strain curves of two groups of elliptical DSCTs. EE-DSTCs [i.e., EC2-ec2-F6 $\left(\varphi_{A}=0.46\right)$, EC2-ec3-F6 $\left(\varphi_{A}=0.37\right)$ and EC2-ec4-F6 $\left.\left(\varphi_{A}=0.28\right)\right]$ are compared in Figure 12(a) while ER-DSTCs [i.e., EC2rc2-F6 $\left(\varphi_{A}=0.46\right)$, EC2-rc3-F6 $\left(\varphi_{A}=0.37\right)$ and EC2-rc4-F6 $\left.\left(\varphi_{A}=0.28\right)\right]$ are compared in Figure 12(b). As shown in Figure 12(a) for EE-DSTCs, specimen EC2-ec2-F6 $\left(\varphi_{A}=0.46\right)$ has the largest peak axial stress and the largest ultimate axial strain, while specimen EC2-ec3-F6 $\left(\varphi_{A}=0.37\right)$ has the smallest peak axial stress and the smallest ultimate axial strain. However, the effect of the void area ratio is quite the opposite for ERDSTCs as shown in Figure 12(b). Nevertheless, within the range examined the void area ratio does not have a significant effect on either the ultimate axial strain or the peak axial stress of the confined concrete. A further experimental study is needed to clarify the effect of the void ratio.

3.7. Effect of Cross-Section of the Steel Tube. Six pairs of elliptical DSTCs are compared in Figure 13 to evaluate the effect of the cross-section shape of the inner steel tube. For elliptical DSTCs with an elliptical inner steel tube, the axial stress-strain curves exhibit a typical bilinear ascending shape with a smooth transition curve connecting the two linear 

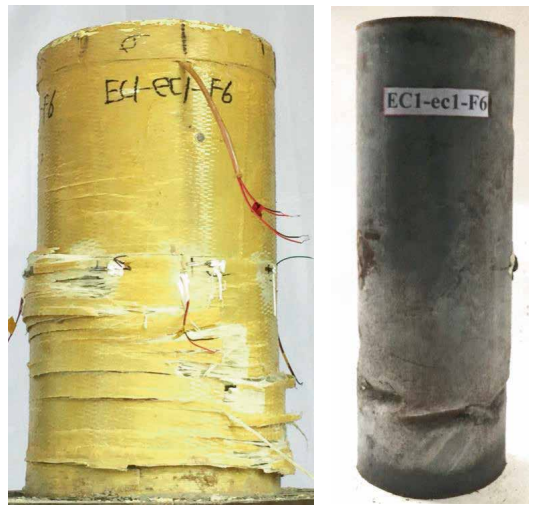

(a)
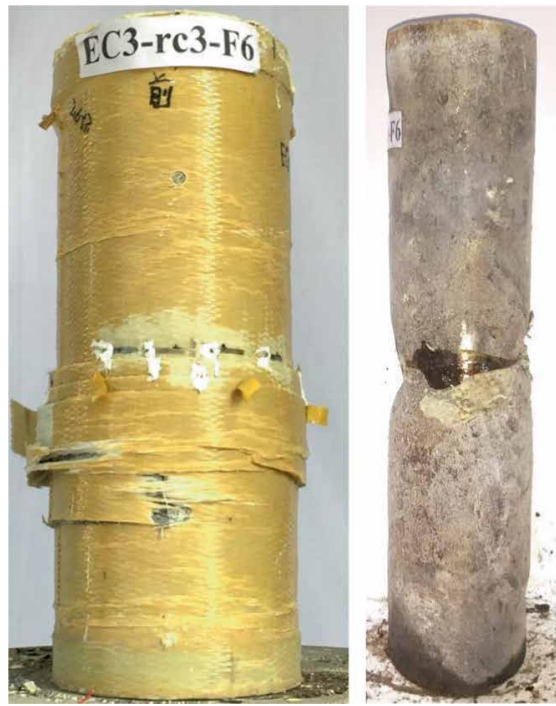

(c)
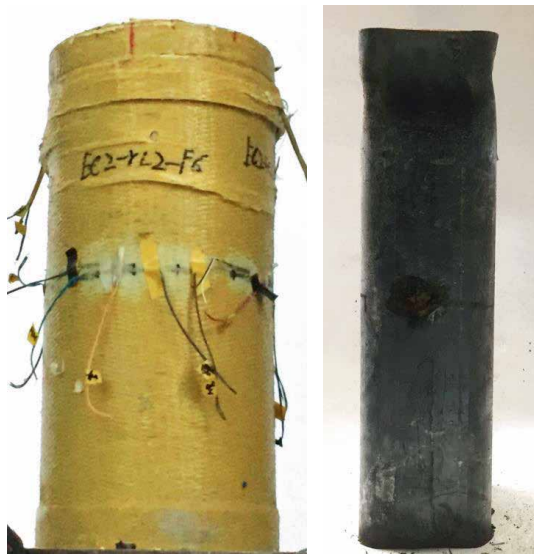

(e)
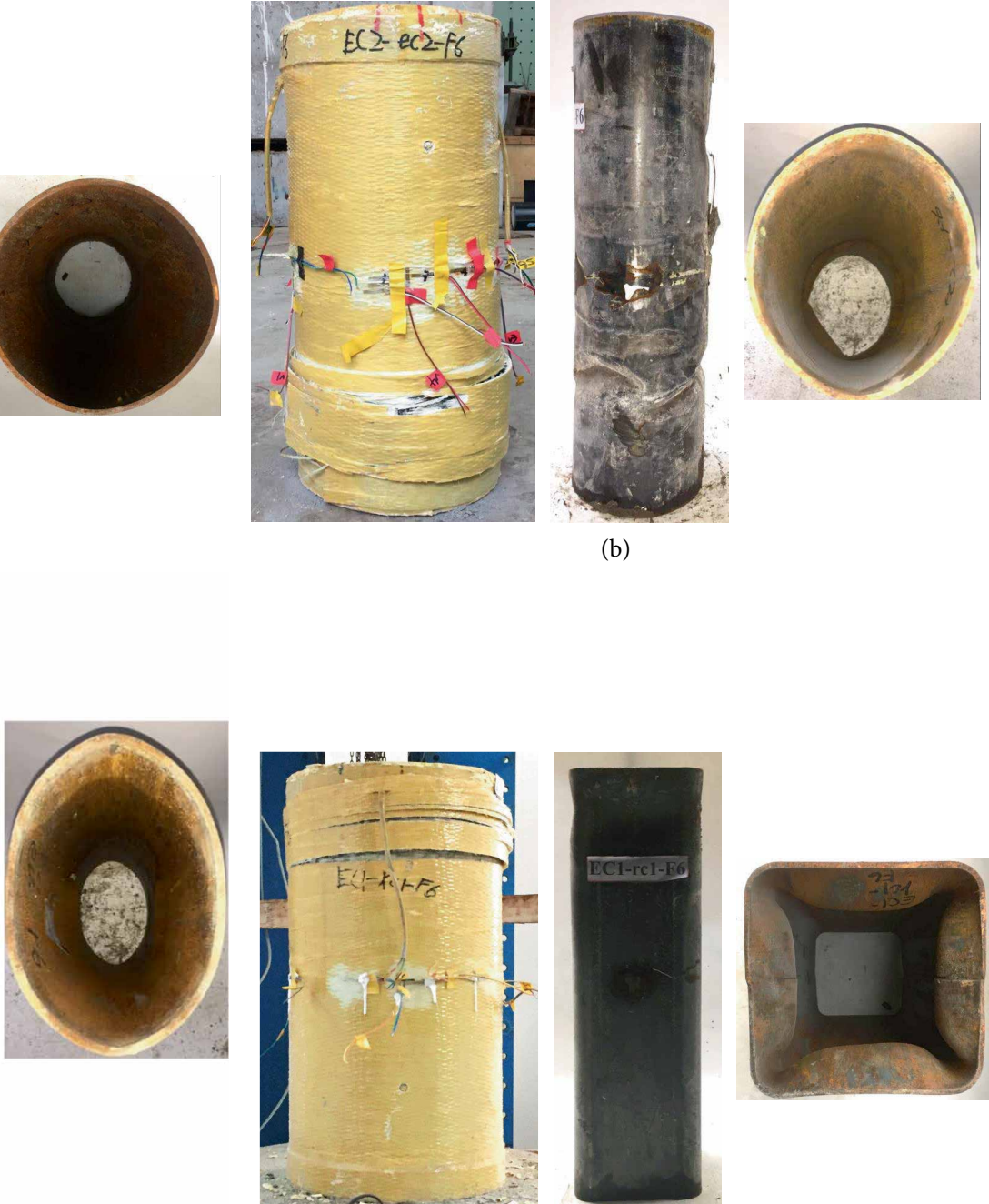

(d)
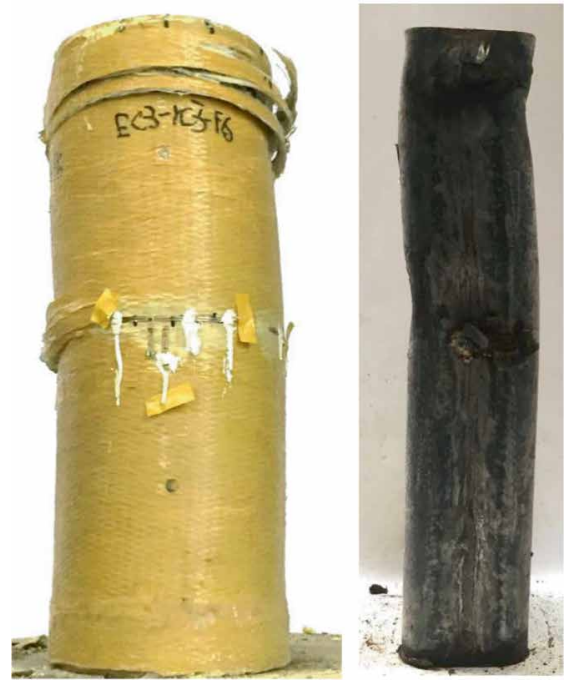

(f)

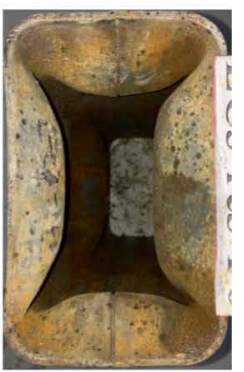

Figure 7: Typical specimens after test. (a) EC1-ec1-F6. (b) EC2-ec2-F6. (c) EC3-ec3-F6. (d) EC1-rc1-F6. (e) EC2-rc2-F6. (f) EC3-rc3-F6.

portions (Figure 13). The axial stress-strain curve of specimen EC1-ec1-F6 has a small descending portion when the axial strain exceeds 0.032 , which is believed to be attributed to the local inward buckling of the inner steel tube. In contrast, elliptical DSTCs with a rectangular inner steel tube display axial stress-strain curves with a linear ascending curve and 


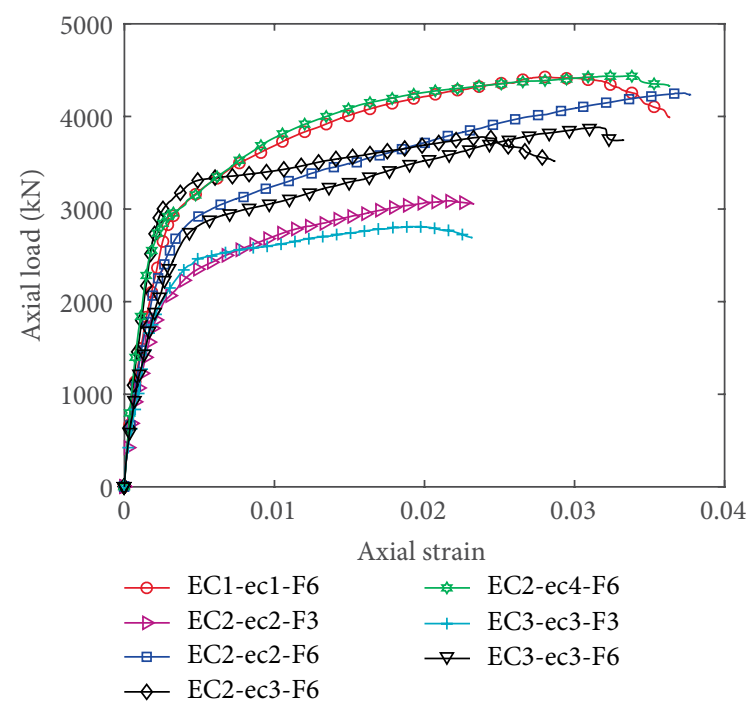

(a)

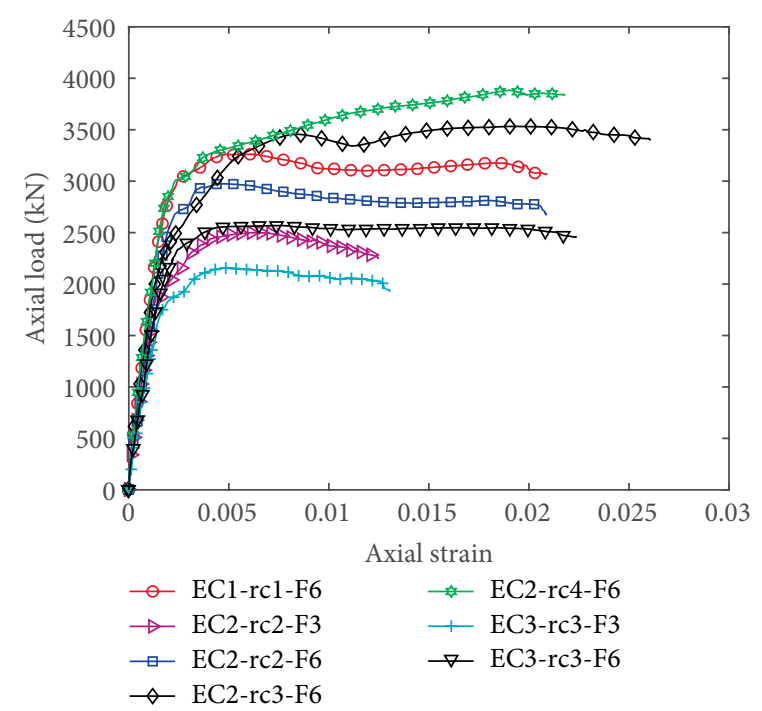

(b)

Figure 8: Axial load-axial strain curves. (a) EE-DSTCs. (b) ER-DSTCs.

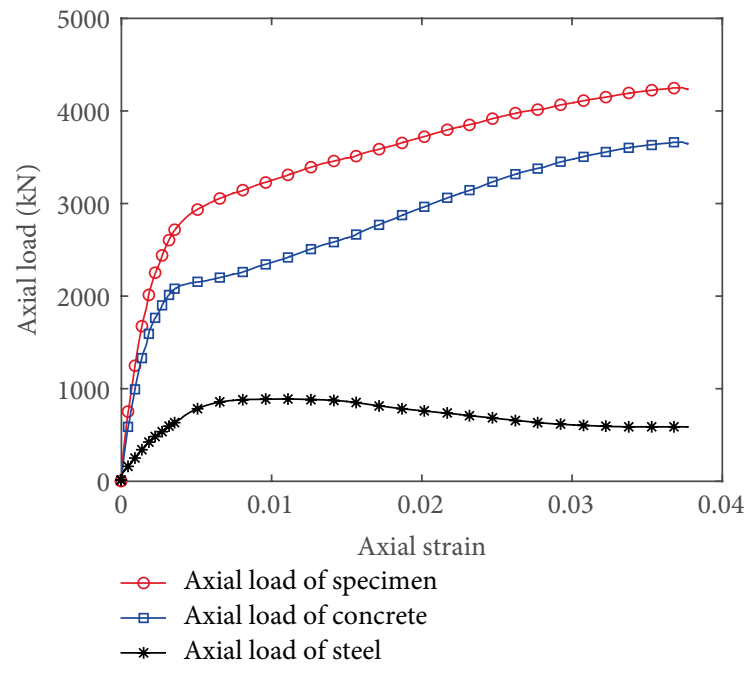

(a)

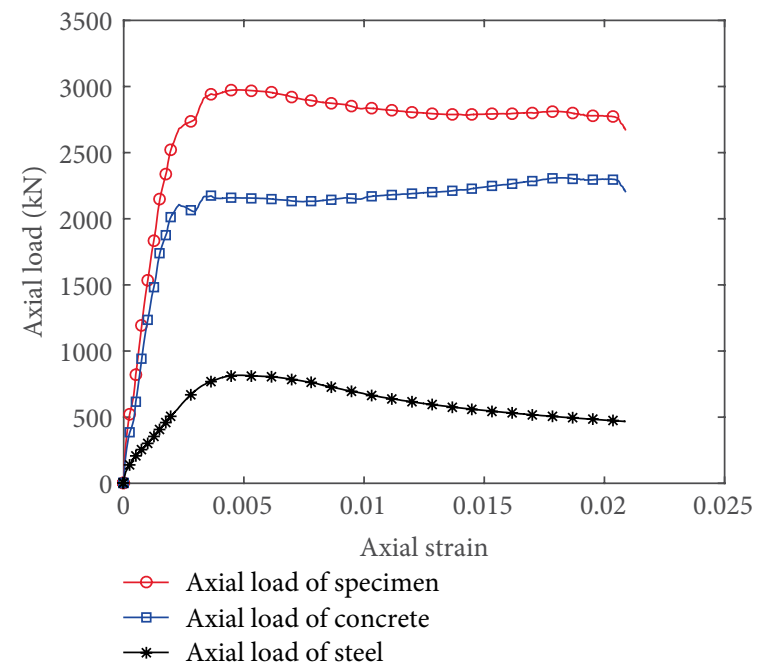

(b)

Figure 9: Axial load taken by the concrete and the steel tube. (a) EC2-ec2-F6. (b) EC2-rc2-F6.

an approximately linear curve with almost constant stress (Figure 13). As shown in Figure 7, the inward buckling of rectangular steel tubes was much severe than that of elliptical steel tubes. Therefore, the confinement effect of ER-DSTCs is much less efficient than that of EE-DSTCs, especially after the development of severe buckling. It is evident that the second portion of the axial stress-strain curves of EE-DSTCs has much larger stiffness due to the effective confinement of both the elliptical FRP tube and the elliptical inner steel tube. However, the second portion of the axial stress-strain curves of ER-DSTCs has a very small stiffness which was mainly due to the severe inward buckling of the inner rectangular steel tube as shown in Figure 7. It is evident that the crosssection shape of the inner steel tube has a significant effect on the axial stress-strain behavior of the confined concrete in elliptical DSTCs. As illustrated in Figure 7 and Table 4, elliptical DSTCs with an elliptical steel tube generally failed at much larger ultimate axial strains and had much large strain enhancement ratios and strength enhancement ratios than corresponding elliptical DSTCs with a rectangular steel tube. Therefore, elliptical DSTCs with an elliptical steel tube exhibit much better ductility and strength enhancement than those specimens with a rectangular steel tube.

\section{Stress-Strain Model}

4.1. Yu et al.'s Model for Circular DSTCs with a Circular Steel Tube. Yu et al. [11] proposed a simple stress-strain model for the confined concrete of circular DSTCs with a circular steel tube (Figure 1(a)), which was based on Teng et al.s [37] stress-strain model for circular FRP-confined solid concrete 
TABLE 4: Key test results.

\begin{tabular}{|c|c|c|c|c|c|c|c|}
\hline Specimen name & $P_{\max }(\mathrm{kN})$ & $f_{c c}(\mathrm{MPa})$ & $\varepsilon_{c u}(\%)$ & $\varepsilon_{\text {hrup }}(\%)$ & $\varepsilon_{\text {hrup,max }}(\%) /$ Location $^{*}$ & $f_{c c} / f_{c o}$ & $\varepsilon_{c u} / \varepsilon_{c o}$ \\
\hline EC1-ec1-F6 & 4424 & 101.9 & 3.64 & 1.74 & $1.91 / \mathrm{H}$ & 2.02 & 14.0 \\
\hline EC2-ec2-F3 & 3090 & 76.2 & 2.33 & 1.34 & $1.61 / \mathrm{B}$ & 1.51 & 8.96 \\
\hline EC2-ec2-F6 & 4253 & 115.5 & 3.78 & 1.35 & $2.33 / \mathrm{H}$ & 2.29 & 14.5 \\
\hline EC2-ec3-F6 & 3778 & 86.0 & 2.87 & 1.43 & $2.30 / \mathrm{F}$ & 1.71 & 11.0 \\
\hline EC2-ec4-F6 & 4438 & 92.3 & 3.64 & 1.43 & $2.05 / \mathrm{B}$ & 1.83 & 14.0 \\
\hline EC3-ec3-F3 & 2811 & 85.8 & 2.32 & 1.21 & $1.48 / \mathrm{I}$ & 1.70 & 8.92 \\
\hline EC3-ec3-F6 & 3883 & 131.7 & 3.33 & 1.26 & $1.69 / \mathrm{F}$ & 2.61 & 12.8 \\
\hline EC1-rc1-F6 & 3262 & 65.6 & 2.09 & 1.00 & $1.09 / \mathrm{B}$ & 1.30 & 8.05 \\
\hline EC2-rc2-F3 & 2500 & 53.8 & 1.25 & 0.98 & $1.29 / \mathrm{C}$ & 1.07 & 4.80 \\
\hline EC2-rc2-F6 & 2974 & 71.5 & 2.09 & 0.95 & $1.29 / \mathrm{C}$ & 1.42 & 8.03 \\
\hline EC2-rc3-F6 & 3532 & 82.5 & 2.61 & 1.53 & $2.38 / \mathrm{C}$ & 1.64 & 10.0 \\
\hline EC2-rc4-F6 & 3883 & 79.1 & 2.18 & 1.49 & $2.19 / \mathrm{H}$ & 1.57 & 8.39 \\
\hline EC3-rc3-F3 & 2156 & 56.2 & 1.31 & 1.29 & $1.94 / \mathrm{A}$ & 1.12 & 5.03 \\
\hline EC3-rc3-F6 & 2568 & 81.3 & 2.24 & 1.20 & $1.50 / \mathrm{I}$ & 1.61 & 8.61 \\
\hline
\end{tabular}

*The planar location of the hoop strain gauge with the maximum hoop rupture strain $\varepsilon_{\text {hrup,max }}$ can be found in Figure $4(\mathrm{a})$.

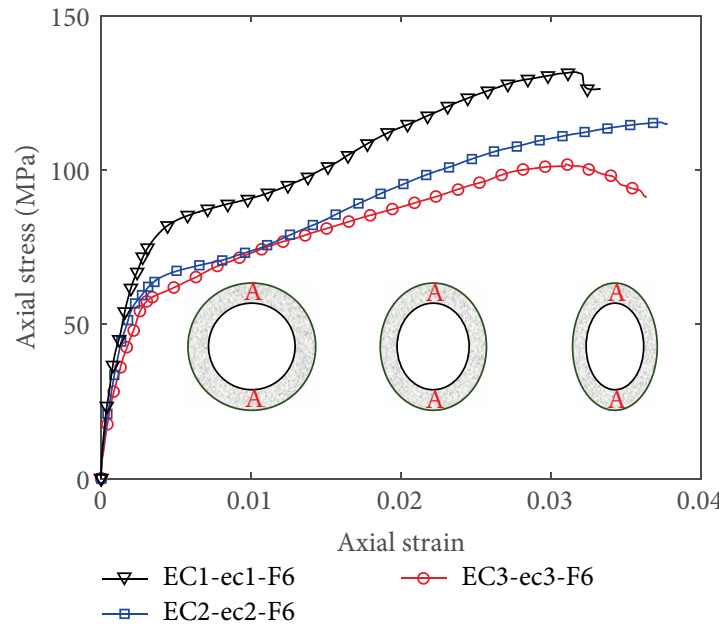

(a)

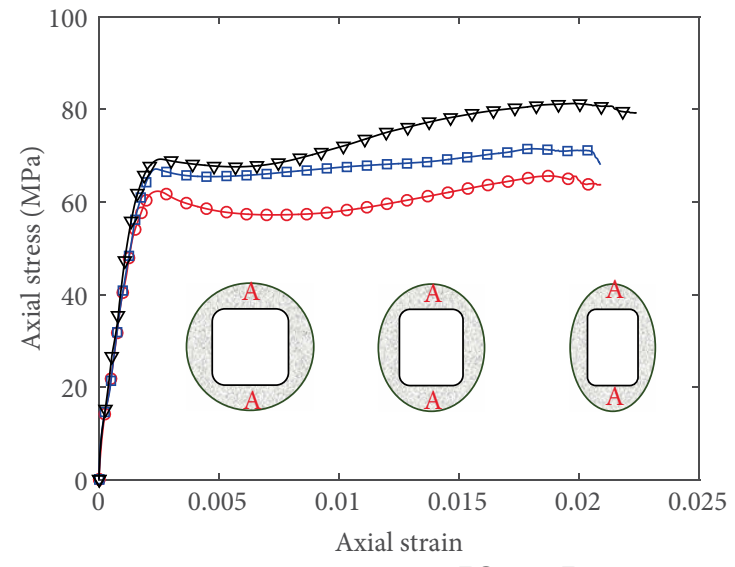

$\rightarrow$ EC1-rc1-F6
$\rightarrow$ EC2-rc2-F6

(b)

FIGURE 10: Effect of cross-sectional aspect ratio. (a) EE-DSTCs. (b) ER-DSTCs.

columns. Based on Yu et al's [11] study, the inner void of circular DSTCs had a negligible effect on the axial stress of the confined concrete. Yu et al's [11] model includes modifications to Teng et al's [37] model to consider the effect of an inner void on the ultimate axial strain of the confined concrete in circular DSTCs. Yu et al's [11] model consists of a parabolic first portion followed by a linear second portion with a smooth transition between the two portions. Equations of Yu et al.s [11] model are as follows:

$$
\begin{gathered}
\sigma_{c}=E_{c} \varepsilon_{c}-\frac{\left(E_{c}-E_{2 c}\right)^{2}}{4 f_{o}} \varepsilon_{c}^{2}, \quad 0 \leq \varepsilon_{c} \leq \varepsilon_{t}, \\
\sigma_{c}=f_{o}+E_{2 c} \varepsilon_{c}, \quad \varepsilon_{t} \leq \varepsilon_{c} \leq \varepsilon_{c u}, \\
\varepsilon_{t}=\frac{2 f_{o}}{E_{c}-E_{2 c}}, \\
E_{2 c}=\frac{f_{c c}^{\prime}-f_{o}}{\varepsilon_{c u}},
\end{gathered}
$$

$$
\begin{gathered}
\frac{f_{c c}^{\prime}}{f_{c o}^{\prime}}= \begin{cases}1+3.5\left(\rho_{K}-0.01\right) \rho_{\varepsilon} & \rho_{K} \geq 0.01 \\
1 & \rho_{K}<0.01,\end{cases} \\
\frac{\varepsilon_{c u}}{\varepsilon_{c o}}=1.75+6.5 \rho_{K}^{0.8} \rho_{\varepsilon}^{1.45}(1-\varphi)^{-0.22}, \\
\frac{f_{l}}{f_{c o}^{\prime}}=\frac{E_{\text {frp }} t_{\text {frp }} \varepsilon_{\mathrm{h}, \mathrm{rup}}}{f_{c o}^{\prime} R}=\rho_{K} \rho_{\varepsilon}, \\
\rho_{K}=\frac{E_{\mathrm{frp}} t_{\mathrm{frp}}}{E_{\text {seco }} R}, \\
\rho_{\varepsilon}=\frac{\varepsilon_{\mathrm{h}, \mathrm{rup}}}{\varepsilon_{c o}}, \\
E_{\text {seco }}=\frac{f_{c o}^{\prime}}{\varepsilon_{c o}},
\end{gathered}
$$




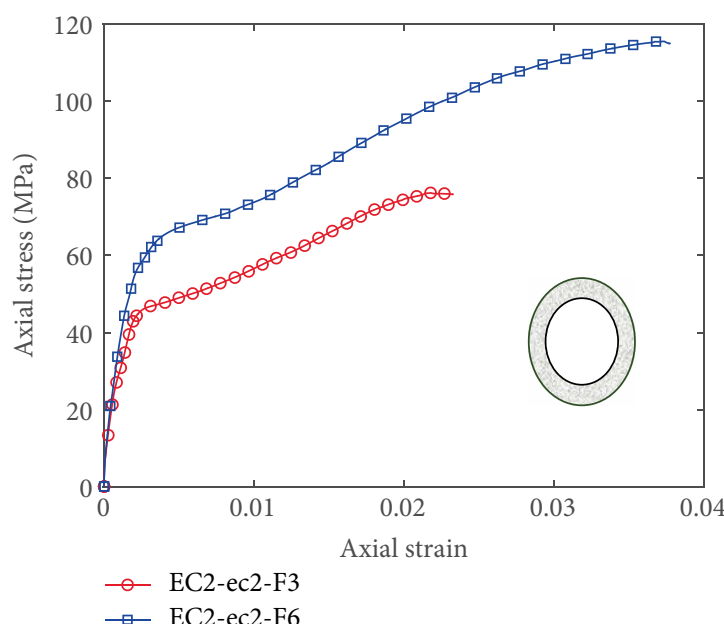

(a)

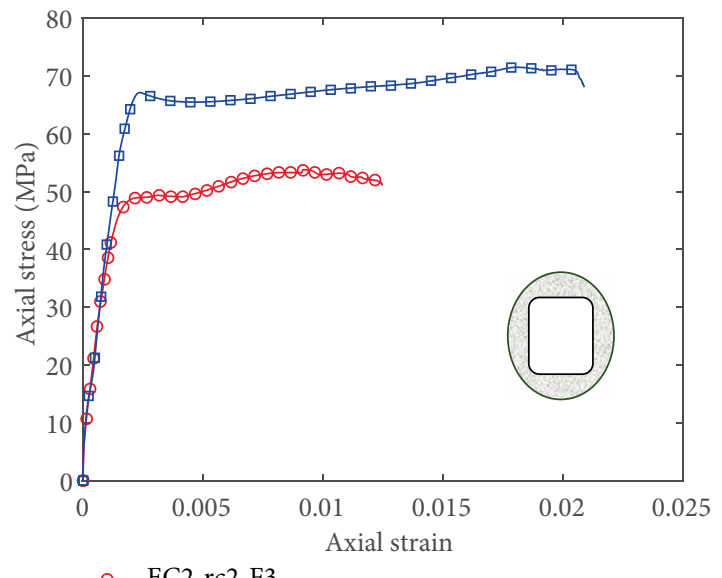

- EC2-rc2-F3

$\square$ EC2-rc2-F6

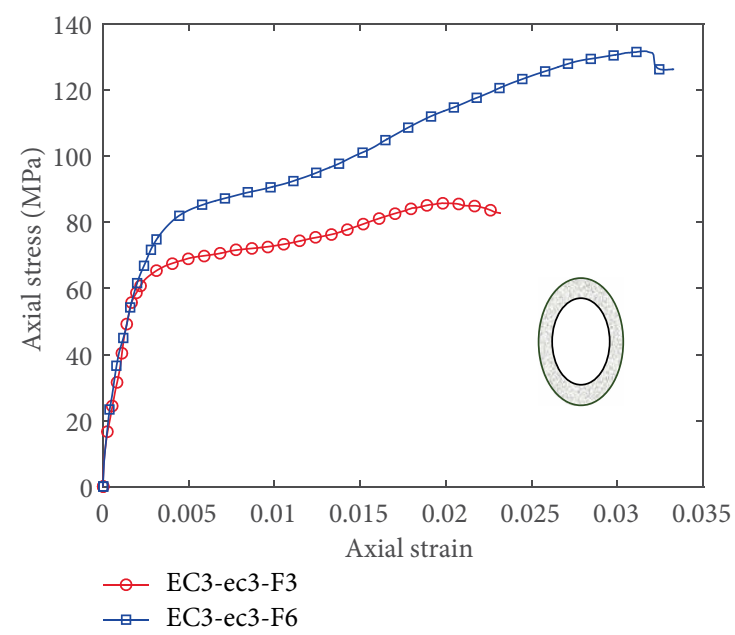

(b)

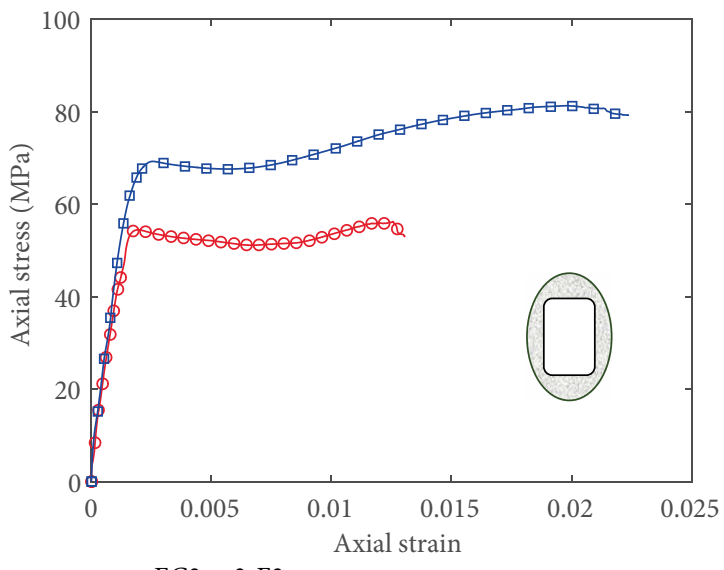

$\rightarrow$ EC3-rc3-F3

$\rightarrow$ EC3-rc3-F6

(c)

(d)

Figure 11: Effect of FRP thickness. (a) EE-DSTCs, $\rho_{A}=1.2$. (b) EE-DSTCs, $\rho_{A}=1.5$. (c) ER-DSTCs, $\rho_{A}=1.2$. (d) ER-DSTCs, $\rho_{A}=1.5$.

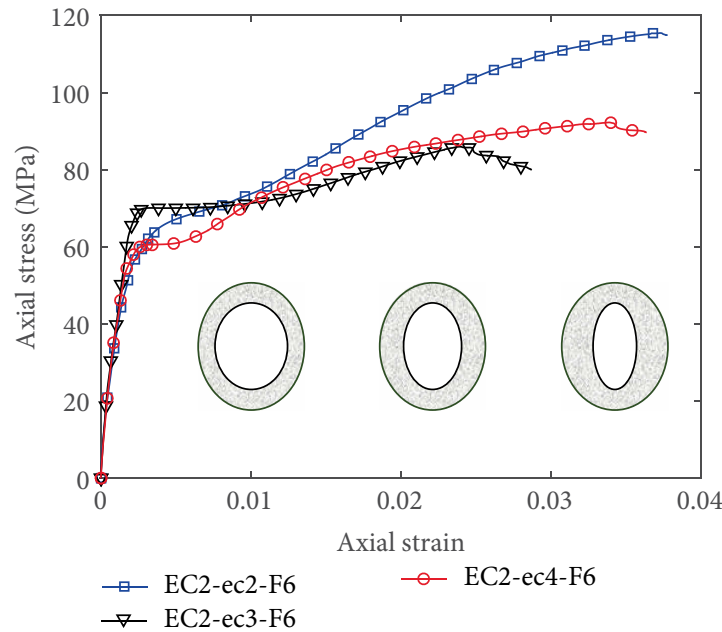

(a)

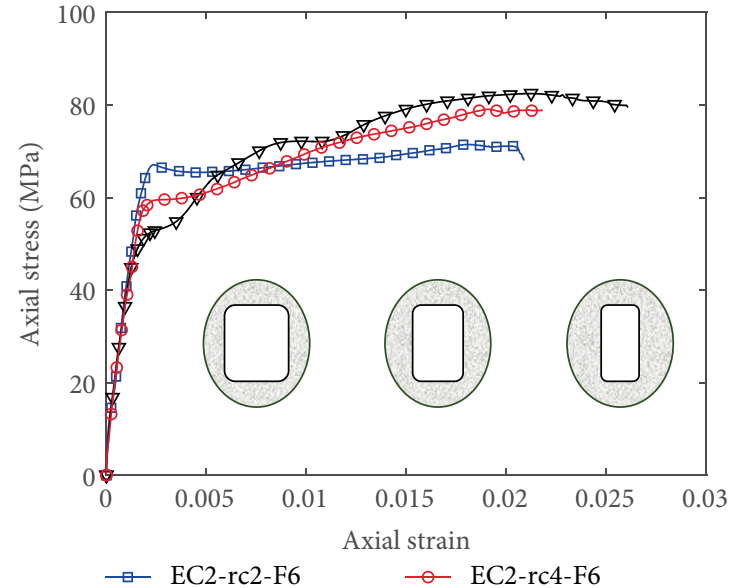

(b)

FIgURE 12: Effect of void area ratio. (a) EE-DSTCs. (b) ER-DSTCs. 


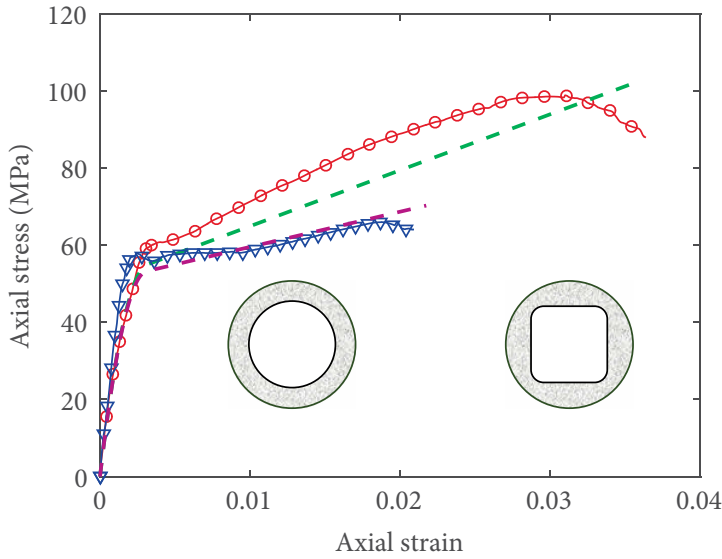

- - EC1-ec1-F6 Test - - EC1-ec1-F6 Prediction $\rightarrow$ EC1-rc1-F6 Test - - EC1-rc1-F6 Prediction

(a)

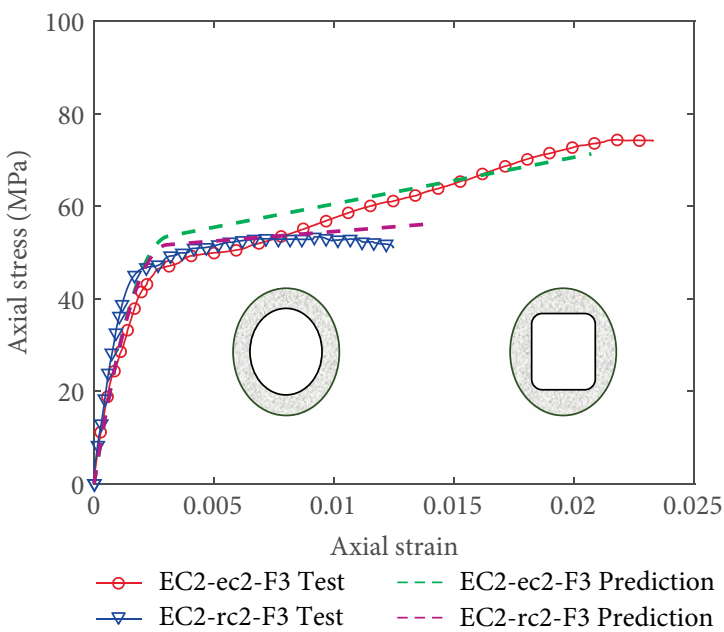

(c)

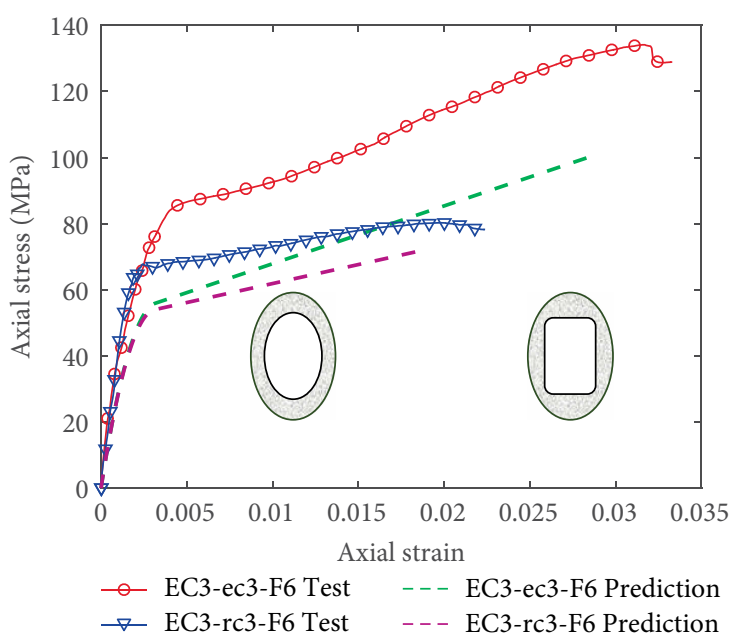

(e)

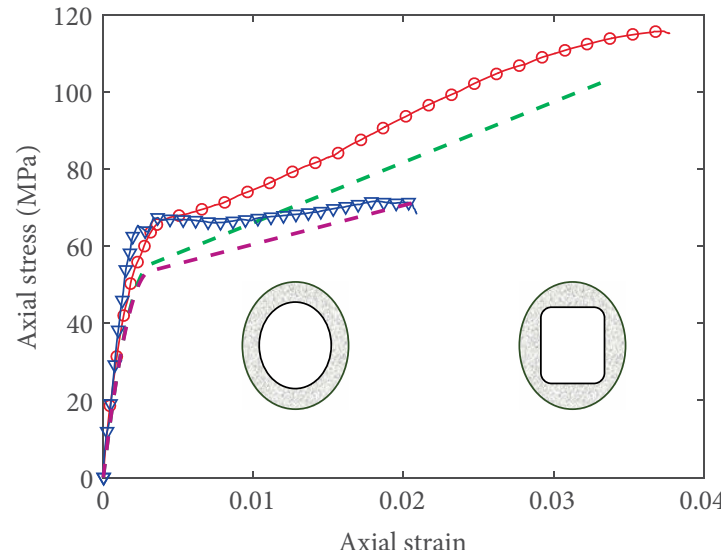

- - EC2-ec2-F6 Test - - EC2-ec2-F6 Prediction

$\rightarrow$ EC2-rc2-F6 Test $\quad--$ EC2-rc2-F6 Prediction

(b)

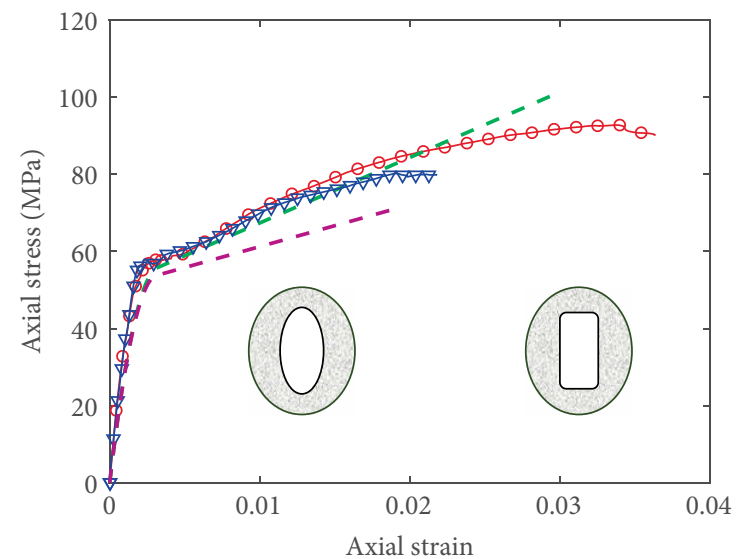

- - EC2-ec4-F6 Test $\quad--$ EC2-ec4-F6 Prediction

$\rightarrow$ EC2-rc4-F6 Test _ - EC2-rc4-F6 Prediction

(d)

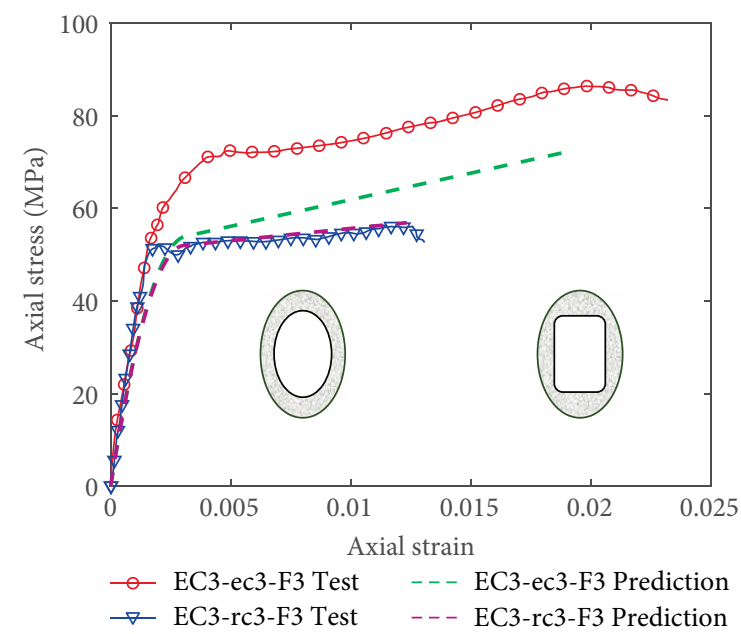

(f)

Figure 13: Effect of inner steel tubes. 


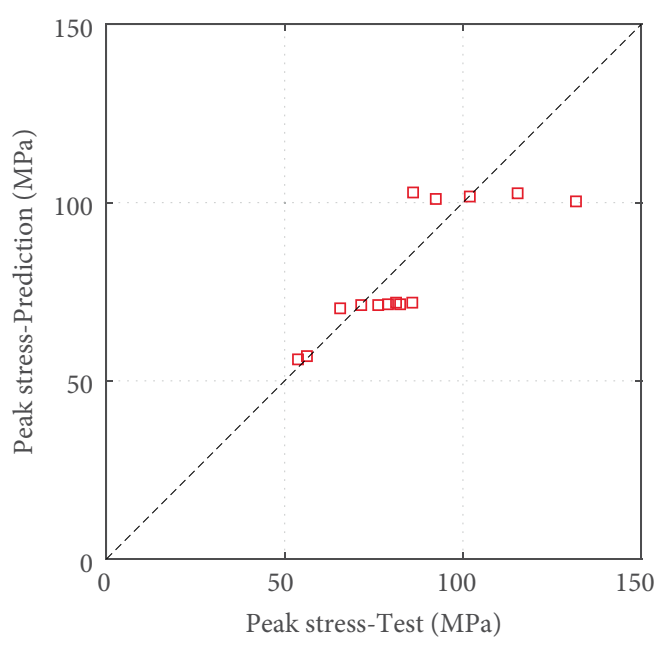

(a)

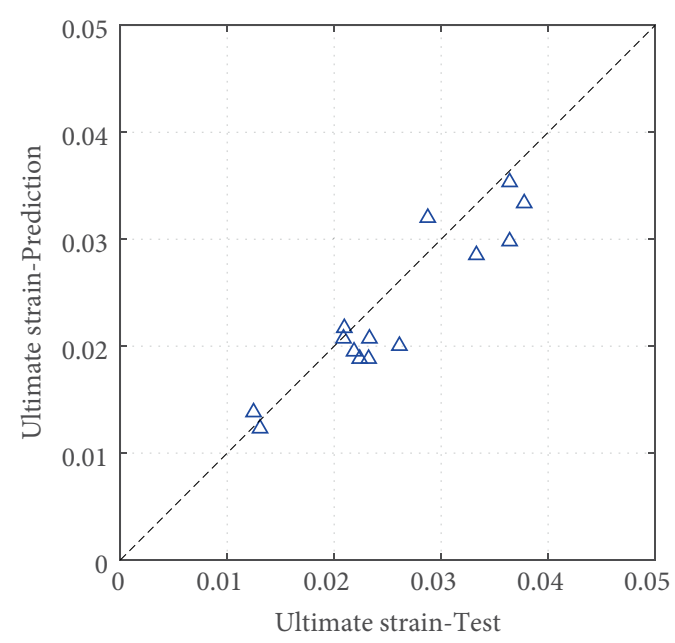

(b)

Figure 14: Predictions of the proposed model. (a) Peak stress. (b) Ultimate strain.

where:

$\sigma_{c}$ and $\varepsilon_{c}$ are the axial stress and the axial strain of confined concrete, respectively;

$f_{c c}^{\prime}$ and $\varepsilon_{c u}$ are the compressive strength and the ultimate axial strain of confined concrete, respectively;

$f_{c o}^{\prime}$ and $\varepsilon_{c o}$ are the compressive strength and the axial strain at peak axial stress of unconfined concrete, respectively;

$f_{o}$ is the intercept of the stress axis by the linear second portion, which is taken to be $f_{c o}^{\prime}$;

$E_{c}$ is the initial elastic modulus of confined concrete;

$E_{2 c}$ is the slope of the linear second portion of the stressstrain curve;

$E_{\text {seco }}$ is the secant modulus of unconfined concrete;

$\varepsilon_{t}$ is the axial strain at the smooth transition point where the parabolic first portion meets the linear second portion;

$\rho_{K}$ and $\rho_{\varepsilon}$ are the confinement stiffness ratio and the strain ratio, respectively;

$E_{\text {frp }}$ is the elastic modulus of FRP in the hoop direction;

$t_{\text {frp }}$ is the thickness of the FRP tube;

$\varepsilon_{\mathrm{h} \text {,rup }}$ is the hoop strain of FRP at the rupture of the tube due to hoop tensile stresses;

$R$ and $D_{c}$ is the outer radius and the outer diameter of the annular concrete section, respectively;

$\varphi$ is the ratio between the outer diameter of the steel tube $d_{s}$ and the outer diameter of the annular concrete section $D_{c}$.

\subsection{Teng et al.'s Model for Elliptical FRP-Confined Solid Concrete}

Columns. Teng et al. [38] proposed a simple stress-strain model for the confined concrete of elliptical FRP-confined solid concrete columns, which was also based on Teng et al.s [37] stress-strain model for circular FRP-confined solid columns. The effect of elliptical aspect ratio on the compressive strength of confined concrete was considered in Teng et al.'s [38] model, which consists Equations (1), (3), (4), (9), and the following equations:

$$
\sigma_{c}=\left\{\begin{array}{ll}
f_{c o}^{\prime}+E_{2 c} \varepsilon_{c} & \rho_{K} \geq 0.01 \\
f_{c o}^{\prime} & \rho_{K}<0.01,
\end{array} \quad \varepsilon_{t} \leq \varepsilon_{c} \leq \varepsilon_{c u},\right.
$$

$$
\begin{gathered}
\frac{f_{c c}^{\prime}}{f_{c o}^{\prime}}=1-K\left(\rho_{K}\right) \rho_{\varepsilon}, \\
K\left(\rho_{K}\right)=\left\{\begin{array}{cc}
-3.5\left(\rho_{K}-0.01\right) & \rho_{K} \geq 0.01 \\
0 & \rho_{K}<0.01,
\end{array}\right. \\
\frac{\varepsilon_{c u}}{\varepsilon_{c o}}=1.75+6.5 \rho_{K}^{0.8} \rho_{\varepsilon}^{1.45}, \\
\rho_{\mathrm{FRP}}=\frac{1.5(a+b)-\sqrt{a b}}{a b} t_{\mathrm{frp}} \\
\rho_{K}=\frac{\rho_{\mathrm{FRP}} E_{\mathrm{frp}} \varepsilon_{c o}}{2 f_{c o}^{\prime}}, \\
\varepsilon_{\mathrm{h}, \text { rup }}=k_{s} k_{\varepsilon} \varepsilon_{f u}, \\
k_{s}=0.5\left(3-\frac{a}{b}\right)
\end{gathered}
$$

where:

$\rho_{\text {FRP }}$ is the FRP volumetric ratio for elliptical FRP-confined solid concrete column;

$\rho_{K}$ is the confinement stiffness ratio with the effect of elliptical aspect ratio considered;

$a$ and $b$ are half of the major axis and the half of the minor axis of elliptical cross-section;

$\varepsilon_{f u}$ is the ultimate tensile strain of FRP from tensile coupon tests;

$k_{\varepsilon}$ is the FRP strain efficiency ratio accounting for the discrepancy between the FRP jacket rupture strain obtained from an FRP-confined concrete column test and that obtained from the flat coupon test; $k_{\varepsilon}$ is taken as 0.70 in Teng et al. (2009);

$k_{s}$ is the shape factor accounting for the effect of cross-sectional shape on the jacket rupture strain for the equivalent circular column. 
4.3. Proposed Model. Yu et al.s [11] model was proposed for circular DSTCs with a circular inner steel tube, whereas Teng et al's [38] model was proposed for elliptical FRP-confined solid concrete columns. Both models were proposed based on Teng et al.s [37] stress-strain model for circular FRP-confined solid columns. The effect of the elliptical aspect ratio could not be reflected in Yu et al's [11] model, while the effect of inner void in elliptical DSTCs could neither be considered in Teng et al's [38] model. Based on the experimental results in the present study, Equations (19) and (20), which are derived through a trial and error process, are proposed to account for the effects of the elliptical aspect ratio, the inner void, and the cross-section shape of the inner steel tube for elliptical DSTCs.

$$
\begin{gathered}
\frac{\varepsilon_{c u}}{\varepsilon_{c o}}=1.75+6.5 \rho_{K}^{0.8} \rho_{\varepsilon}^{1.45}\left(1-\sqrt{\varphi_{A}}\right)^{-0.22}, \\
\rho_{\mathrm{FRP}}=\frac{1.5(a+b)-\sqrt{a b}}{a b} t_{\mathrm{frp}} k_{t},
\end{gathered}
$$

where:

$\varphi_{A}$ is the void area ratio, which the ratio between the area of the concrete void and the area of the outer elliptical section of concrete;

$k_{t}$ is the shape factor of the inner steel tube; $k_{t}$ is taken to be 1.0 and 0.5 for an elliptical inner steel tube and a rectangular inner steel tube, respectively.

To summarize, the proposed stress-strain model for confined concrete in elliptical DSTCs includes Equations (19) and (20) proposed in the present study and Equations (1), (3), (4), (9), (11)-(13), (16)-(18). The void area ratio $\varphi_{A}$ in Equation (19) (i.e., the ratio between the area of the concrete void and the area of the outer elliptical section of concrete), is different from the void ratio $\varphi$ in Equation (6) of Yu et al.s [11] model which is defined as the ratio between the outer diameter of the steel tube $d_{s}$ and the outer diameter of the annular concrete section $D_{c}$. Equation (19) is degraded to Equation (6) for circular DSTCs. $k_{t}$ is the shape factor of the inner steel tube. $k_{t}$ is taken to be 1.0 for an elliptical inner steel tube, but is 0.5 for a rectangular inner steel tube to account for the negative effect of the significant inward buckling of the rectangular steel tube. For elliptical FRP-confined solid concrete columns, Equations (19) and (20) are degraded to Equations (14) and (15), respectively.

The axial stress-axial strain curves of experimental results are compared with predictions of the proposed model in Figure 13. The FRP rupture strain obtained from the flat coupon test was used in all predictions following Equation (17) as suggested in Teng et al.'s [38] model. It is evident that the proposed model produces approximately bilinear axial stress-strain curves for the confined concrete of elliptical DSTCs which are in close agreement with the experimental stress-strain curves. The predicted peak stress and ultimate strain of the confined concrete in elliptical DSTCs are compared with the predictions of the proposed model in Figure 14. It is evident, the proposed model is capable of providing reasonably accurate but generally conservative predictions.

\section{Conclusions}

This paper presents an experimental study on elliptical DSTCs under monotonic axial compression. The test results and discussions allow the following conclusions to be drawn:

(1) The elliptical aspect ratio has no obvious effect on the ultimate axial strain of the confined concrete in elliptical DSTCs, whereas the averaged peak stress increases with the increase of the elliptical aspect ratio.

(2) Elliptical DSTCs with an elliptical steel tube exhibit much better ductility and strength enhancement than those elliptical DSTCs with a rectangular steel tube.

(3) Elliptical DSTCs with a thicker FRP tube generally have higher averaged peak stress and larger ultimate axial strain of the confined concrete.

(4) Within the range examined the void area ratio does not have a significant effect on either the ultimate axial strain or the peak axial stress of the confined concrete.

(5) Based on Yu et al.s model for circular DSTCs with a circular inner steel tube and Teng et al.'s model for elliptical FRP-confined solid concrete columns, a simple stress-strain model of confined concrete was proposed for elliptical DSTCs, which can provide reasonably accurate but generally conservative predictions.

\section{Data Availability}

The experimental data presented in the paper is obtained by the authors. All the test data is available by sending an email to the corresponding author.

\section{Conflicts of Interest}

The authors declare that they have no conflicts of interest.

\section{Acknowledgments}

The authors are grateful for the financial support received from the National Natural Science Foundation of China (Grant Nos. $51608263,51778102)$, and the Natural Science Foundation of Jiangsu Province (Grant No. BK20160998).

\section{References}

[1] L. C. Hollaway and J. G. Teng, Strengthening and Rehabilitation of Civil Infrastructures Using Fibre Reinforced Polymer (FRP) Composites, Woodhead Publishing, Cambridge, UK, 2008.

[2] M. Motavalli and C. Czaderski, "FRP composites for retrofitting of existing civil structures in Europe: state-of-the-art review," in Proceedings, International Conference of Composites and Polycon, pp. 1-10, American Composites Manufacturers Association, Tampa, FL, USA, 2007.

[3] L. C. Bank, Composites for Construction: Structural Design with FRP Materials, John Wiley \& Sons, West Sussex, UK, 2006. 
[4] J. J. Xu, Z. P. Chen, Y. Xiao, C. Demartino, and J. H. Wang, "Recycled aggregate concrete in FRP-confined columns: a review of experimental results," Composite Structures, vol. 174, pp. 277-291, 2017.

[5] H. Nordin and B. Taljsten, "Testing of hybrid FRP composite beams in bending," Composites Part B: Engineering, vol. 35, no. 1, pp. 27-33, 2004.

[6] J. G. Teng, "New-material hybrid structures," China Civil Engineering Journal, vol. 51, no. 12, pp. 1-11, 2008.

[7] Y. L. Wang, G. H. Cai, Y. Y. Li, D. Waldmann, A. S. Larbi, and K. D. Tsavdaridis, "Behavior of circular fiber-reinforced polymer-steel-confined concrete columns subjected to reversed cyclic loads: experimental studies and finite-element analysis," Journal of Structural Engineering, vol. 145, no. 9, Article ID 04019085, 2019.

[8] J. G. Teng, T. Yu, and Y. L. Wong, "Behaviour of hybrid FRPconcrete-steel double-skin tubular columns," in Proceedings, Second International Conference on FRP Composites in Civil Engineering, pp. 811-818, Adelaide, Australia, 2004.

[9] J. G. Teng, T. Yu, Y. L. Wong, and S. L. Dong, "Hybrid FRP-concretesteel tubular columns: concept and behavior," Construction and Building Materials, vol. 21, no. 4, pp. 846-854, 2007.

[10] T. Yu, Behavior of Hybrid FRP-concrete-steel double-skin tubular columns [PhD Thesis], The Hong Kong Polytechnic University, Hong Kong, 2007.

[11] T. Yu, J. G. Teng, and Y. L. Wong, "Stress-strain behavior of concrete in hybrid FRP-concrete-steel double-skin tubular columns," Journal of Structural Engineering, vol. 136, no. 4, pp. 379-389, 2010.

[12] B. Zhang, T. Yu, and J. G. Teng, "Axial compression tests on hybrid double-skin tubular columns filled with high strength concrete," in Proceedings, Third International Postgraduate Conference on Infrastructure and Environment, pp. 171-176, Hong Kong, China, 2011.

[13] B. A. L. Fanggi and T. Ozbakkaloglu, "Compressive behavior of aramid FRP-HSC-steel double-skin tubular columns," Construction and Building Materials, vol. 48, pp. 554-565, 2013.

[14] J. N. Zheng and T. Ozbakkaloglu, "Sustainable FRP-recycled aggregate concrete-steel composite columns: behavior of circular and square columns under axial compression," ThinWalled Structures, vol. 120, pp. 60-69, 2017.

[15] B. Zhang, Hybrid FRP-concrete-steel double-skin tubular columns under static and cyclic loading [PhD Thesis], The Hong Kong Polytechnic University, Hong Kong, 2014.

[16] B. Zhang, J. G. Teng, and T. Yu, "Compressive behavior of double-skin tubular columns with high-strength concrete and a filament-wound FRP tube," Journal of Composites for Construction, vol. 21, no. 5, p. 04017029, 2017.

[17] T. Yu, B. Zhang, Y. B. Cao, and J. G. Teng, "Behavior of hybrid FRP-concrete-steel double-skin tubular columns subjected to cyclic axial compression," Thin-Walled Structures, vol. 61, pp. 196-203, 2012.

[18] T. Ozbakkaloglu and E. Akin, "Behavior of FRP-confined normal-and high-strength concrete under cyclic axial compression," Journal of Composites for Construction, vol. 16, no. 4, pp. 451-463, 2012.

[19] T. Ozbakkaloglu and B. A. L. Fanggi, "FRP-HSC-steel composite columns: behavior under monotonic and cyclic axial compression," Materials and Structures, vol. 48, no. 4, pp. 1075-1093, 2013.
[20] P. Xie, Behavior of large-scale hybrid FRP-concrete-steel doubleskin tubular columns subjected to concentric and eccentric compression [PhD Thesis], The Hong Kong Polytechnic University, Hong Kong, 2018.

[21] T. Yu, Y. L. Wong, and J. G. Teng, "Behavior of hybrid FRPconcrete-steel double-skin tubular columns subjected to eccentric compression," Advances in Structural Engineering, vol. 13, no. 5, pp. 961-974, 2010.

[22] L. H. Han, Z. Tao, F. Y. Liao, and Y. Xu, "Tests on cyclic performance of FRP-concrete-steel double-skin tubular columns," Thin-Walled Structures, vol. 48, no. 6, pp. 430-439, 2010.

[23] B. Zhang, J. G. Teng, and T. Yu, "Experimental behavior of hybrid FRP-concrete-steel double-skin tubular columns under combined axial compression and cyclic lateral loading," Engineering Structures, vol. 99, pp. 214-231, 2015.

[24] I. A. Omar, M. A. ElGawady, G. Ahmed, A. Sujith, and A. Mohanad, "Seismic performance of innovative hollowcore FRP-concrete-steel bridge columns," Journal of Bridge Engineering, vol. 22, no. 2, Article ID 04016120, 2017.

[25] Y. Idris and T. Ozbakkaloglu, "Behavior of square fiber reinforced polymer-high-strength concrete-steel double-skin tubular columns under combined axial compression and reversed-cyclic lateral loading," Engineering Structures, vol. 118, pp. 307-319, 2016.

[26] R. Wang, L. H. Han, and Z. Tao, "Behavior of FRP-concrete-steel double skin tubular members under lateral impact experimental study," Thin-Walled Structures, vol. 95, pp. 363-373, 2015.

[27] I. A. Omar and M. A. ElGawady, "Performance of hollowcore FRP-concrete-steel bridge columns subjected to vehicle collision," Engineering Structures, vol. 123, pp. 517-531, 2016.

[28] Y. W. Zhou, X. M. Liu, F. Xing, D. W. Li, Y. C. Wang, and L. L. Sui, "Behavior and modeling of FRP-concrete-steel double-skin tubular columns made of full lightweight aggregate concrete," Construction and Building Materials, vol. 139, pp. 52-63, 2017.

[29] J. J. Zeng, J. F. Lv, G. Lin, Y. C. Guo, and L. J. Li, "Compressive behavior of double-tube concrete columns with an outer square FRP tube and an inner circular high-strength steel tube," Construction and Building Materials, vol. 184, pp. 668-680, 2018.

[30] K. D. Peng, T. Yu, N. S. Muhammad, and L. Huang, "Compressive behavior of hybrid double-skin tubular columns with a ribstiffened steel inner tube," Composite Structures, vol. 204, pp. 634-644, 2018.

[31] L. Zeng, L. J. Li, Z. Su, and F. Liu, "Compressive test of GFRPrecycled aggregated concrete-steel tubular long columns," Construction and Building Materials, vol. 176, pp. 295-312

[32] T. Yu, S. Zhang, S. L. Huang, and C. W. Chan, "Compressive behavior of hybrid double-skin tubular columns with a large rupture strain FRP tube," Composite Structures, vol. 171, pp. 1018, 2017.

[33] B. Zhang, G. Feng, S. W. Wei, N. Y. Zhang, Q. B. Zhang, and X. M. Hu, "Behavior of elliptical GFRP-concrete-steel doubleskin tubular columns under axial compression," Journal of Building Structures, 2019.

[34] ASTM C39/C39M, Standard test method for compressive strength of cylindrical concrete specimens, American Society for Testing and Materials, Philadelphia, PA, USA, 2008.

[35] ASTM D3039/D3039M, Standard test method for tensile properties of polymer matrix composite materials, American Society for Testing and Materials, Philadelphia, PA, USA, 2017. 
[36] BS 18, Tensile Testing of Metals (Including Aerospace Materials), British Standards Institution, London, UK, 1987.

[37] J. G. Teng, T. Jiang, L. Lam, and Y. Z. Luo, "Refinement of a design-oriented stress-strain model for FRP-confined concrete," Journal of Composites for Construction, vol. 13, no. 4, pp. 269-278

[38] J. G. Teng, J. Y. Wu, S. Casalboni, Q. G. Xiao, and Y. Zhao, "Behavior and modeling of fiber-reinforced polymer-confined concrete in elliptical columns," Advances in Structural Engineering, vol. 19, no. 9, pp. 1359-1378, 2016. 